Published in S.C. Levinson and D. Wilkins (Eds.), 2006 Grammars of space. Cambridge: Cambridge University Press.

\title{
$7 \quad$ A sketch of the grammar of space in Tzeltal
}

\section{Penelope Brown}

\subsection{Introduction}

\subsubsection{Space in Mayan languages}

Mayan languages and cultures have a reputation for having highly elaborated conceptions of space and time. Two largely independent streams of research converge on this point: on the one hand, there are several articles and monographs exploring modern-day versions of ancient Mayan calendrical, divination, ritual and cosmological systems in their spatial and temporal dimensions (Villa Rojas 1973, Gossen 1974, 1986, Tedlock 1982, Vogt 1976). On the other hand, a number of scholars have argued that Mayan languages have highly developed - indeed, hypertrophic - linguistic resources for handling spatial concepts, which are particularly evident in the positional roots, directionals and numeral classifiers that most Mayan languages display in some form (Berlin 1968. Norman 1973, Martin 1977, 1979, England 1978). It has been argued that space is a 'grammatical theme' in Mayan languages, that is, an 'underlying organizational principle' that pervades the grammar (England 1978: 226); it is also a cultural theme pervading Mayan ethnographies. And, England argues, where such correspondences between linguistic and cultural themes are found, we are justified in expecting to find 'a substantial and powerful aspect of the world view of a particular group' (Ibid.).

Some recent work attempts more systematically to link these two streams, the linguistic and the ethnographic. A good example is Hanks' (1990) analysis of the deictic system of a group of Yucatec Mayan speakers, embedded in the ethnography of how these Yucatec Mayans conceptualize domestic and local spaces and how they operate in their physical and social world. And, over the past fourteen years, a systematic exploration of spatial concepts in several Mayan languages and cultures (Yucatec, Mopan, Tzotzil and Tzeltal) has been undertaken within the Space Project of the Max Planck Institute for Psycholinguistics. The present paper summarizes the results of this research for Tzeltal. How do Tzeltal speakers talk about the location, position, disposition and movement of things around them? How do they discriminate between two 
similar objects in space, and uniquely refer to one, so that another person can identify the referent (other than by pointing, etc.)? This paper reports the results of field research focussed on these questions, carried out in collaboration with Stephen Levinson in the Tzeltal-speaking Mayan community of Tenejapa, in Chiapas, Mexico. The paper is largely descriptive; some of the broader theoretical implications are developed in other papers. ${ }^{1}$

A number of startling discoveries emerged during this field research, suggesting to us that Tzeltal speakers do indeed conceptualize spatial categories and relations in ways which contrast radically with those familiar to us through Indo-European languages and cultures. The most important features we have discovered are summarized here:

1. Many Tzeltal verbal roots have 'portmanteau' meanings which include a spatial element, that is features of space/shape/configuration/position are compounded with other semantic features in one root. This is true not only of 'positional' roots, as has often been described for Mayan languages, but also for many transitive verb roots. Stative forms of such 'dispositional' predicates $^{2}$ are among the chief resources for describing the location of objects in the interactors' immediately visible surroundings. That is, the unmarked reply to a question of the form: 'Where is the X?' (where $\mathrm{X}$ is a potentially movable entity, i.e. it could in principle be in different places) uses a dispositional predicate to describe how the object is standing, lying, sitting, resting, leaning, or in what size or shape container it is, or in what particular configuration it appears. Spatial relational information specifying where an object is located is often provided largely by the predicate.

2. Adopting the terminology suggested by Talmy (1983) for analysing spatial descriptions, we also observe the following apparent consequence of relying on dispositional roots with such 'portmanteau' semantics: in Tzeltal locative descriptions there is a strong emphasis on describing the figure (the object being located), and a relative de-emphasis on the ground (the thing with respect to which the object is being located). That is, the preferred description of the location of a moveable entity emphasizes the disposition of the figure in space, e.g. how it is upside down, folded, crumpled, etc.

1 This paper has a long history. The first descriptions of the Tzeltal spatial resources discussed here were presented by P. Brown and by S. C. Levinson at a Workshop on Spatial Conceptualization in Mayan Languages and Action, sponsored by the Max Planck Projektgroppe für Kognitive Anthropologie, Berlin, in September 1990, which appeared as working papers (Levinson and Brown 1990, Brown 1991). Later elaborations reporting on the results of jointly developed stimuli are to be found in Brown 1993, 1994, 2000, 2002; Brown and Levinson 1992, 1993a,b,c, 2000, in preparation; Levinson 1994, 1996a,b, 2003, Levinson and Brown 1994, Bohnemeyer and Brown forthcoming.

2 I have labelled the stative forms of these verbs 'dispositional' predicates (Brown 1994, Bohnemeyer and Brown, forthcoming) in order to cover both those derived from positional roots and those from transitive and T/P (intermediate) roots which have a stative (adjectival) - $V l$ form with a special plural form with -ajtik; this is the primary diagnostic for dispositionals. 
3. When an object's location is related explicitly to some ground, there is a dispreference for using participants in the speech event for this purpose that is, there is an avoidance of deictic centring. The deictic system is underdeveloped and underused for this purpose (although it is used extensively for others, for example in reference tracking, or for describing the locations of unmoveable objects and places). Rather, the tendency is to locate objects by reference to the nearest other object - i.e. to use the ground object most proximal to the figure. For precision, use can be made of the extension of body-part imagery to all objects; the ground object is given a 'body', and the figure is related to one of its parts (e.g. 'The gourd is sitting at the lips of the fire.')

4. By contrast, when Tzeltal speakers talk about things in motion, deictic centring plays a key role: motion verbs - whether or not they are inherently deictic - are very often accompanied by a 'directional', a deverbal modifier specifying the direction of action towards or away from (or across) some origo, normally given by the participants' current location.

5. Tzeltal speakers display an absolute orientation using the 'geocentric' system described by the words for 'uphill' (ajk'ol) and 'downhill' (alan), and given by the slope of the terrain which - in the region where we worked corresponds roughly to south and north, respectively. Things can be located on this dimension relative to any origo; it is thus possible to specify locations in relation to any ground object without deictic anchoring ('it's downhill from the schoolhouse', 'it's uphill from the tree', for example). However, the crossways dimension (perpendicular to the uphill-downhill one, i.e. 'across the valley/ridge') does not discriminate between the two sides: ta jejch means acrossways either eastwards or westwards. Similarly, no distinction is made between left and right; an object on either side of a ground object is either identically described ( $t a x u j k$, 'at its side'), or related to a landmark outside the local interactional scene ('it's towards the sunset/the red cliff/the big tree', for example.)

In this report I present the data and analysis which supports these points. Section 7.2 sketches the grammatical structure of the language insofar as it is relevant to spatial description. Section 7.3 focusses on how Tenejapan Tzeltal/speakers make static locative descriptions. It also explores in a preliminary fashion the role of predicates, especially 'dispositionals', in specifying topological relations, and the role of body-part and other relational nouns in narrowing down the search space for locating objects. Section 7.4 looks at how motion is expressed in Tzeltal, contrasting the semantics of motion verbs and directionals with the semantics of words for describing static location. In Section 7.5 the 'uphill/ downhill' absolute frame of reference is described. The conclusion summarizes the facts as we understand them, discusses the surprises in this area and considers their implications. 


\subsubsection{Ethnographic context}

Tzeltal is a Mayan language spoken in the eastern highlands of Chiapas, Mexico, by around 200,000 speakers. The precipitous mountain terrain in this area slopes overall downwards towards the north or west, providing the basis for the uphill/downhill absolute system (see Figure 7.1). The Tzeltal region is contiguous with the other Mayan languages of this area: Tzotzil just to the west, Chol to the north and Tojolabal to the south-east. The region is populated largely by illiterate Mayan peasants living in their own indigenous communities; there are also several Ladino (predominantly Spanish-speaking) towns. Some Tzeltal speakers are partially bilingual in Spanish, and some in Tzotzil, but many (including most women) over the age of thirty are effectively monolingual. The language is still very viable; most children grow up in a monolingual environment until they go to school, the first two years of which are in Tzeltal (at least in schools in the indigenous communities). After children leave school (usually after the sixth grade) most of them rarely use Spanish except on visits to the local Ladino town. There are a few Tzeltal and other Mayan language radio programmes (but no television in indigenous languages, to date), and there is an active programme sponsoring literacy and literature in the native languages. ${ }^{3}$

The data on which this paper is based was collected over a period of fourteen years in the Tzeltal community of Tenejapa, mainly in the northernmost hamlet of Majosik'. The data consists of naturally occurring Tzeltal spatial descriptions in everyday contexts, in the household, on the trails, in the fields, as well as examples systematically elicited in response to our group elicitation tools and 'space games'.

\subsection{Grammatical resources for spatial description}

\subsubsection{Basic grammar}

Tzeltal is a VOS language, mildly polysynthetic, with both prefixes and suffixes. Consistent (non-split) ergative/absolutive cross-referencing of core arguments is obligatory on the verb, and the set of ergative prefixes does double-duty as markers of possession on nouns. There is no case marking to distinguish the various roles of NPs as arguments of the verb; since ellipsis of nominal arguments is extensive, one relies largely on phrase order and context to distinguish whether an NP following the verb is object, subject or other. There is only one preposition, the omni-purpose $t a$, which introduces instrumental, purpose, manner, time and place adverbials after the verb. Place adverbials with $t a$ occur

3 This is based in Sna Jtz'ibajom, 'The House of the Writer', in the local town of San Cristóbal de las Casas. It does not (yet) effect most members of the Mayan communities, many of whom do not know of its existence. 


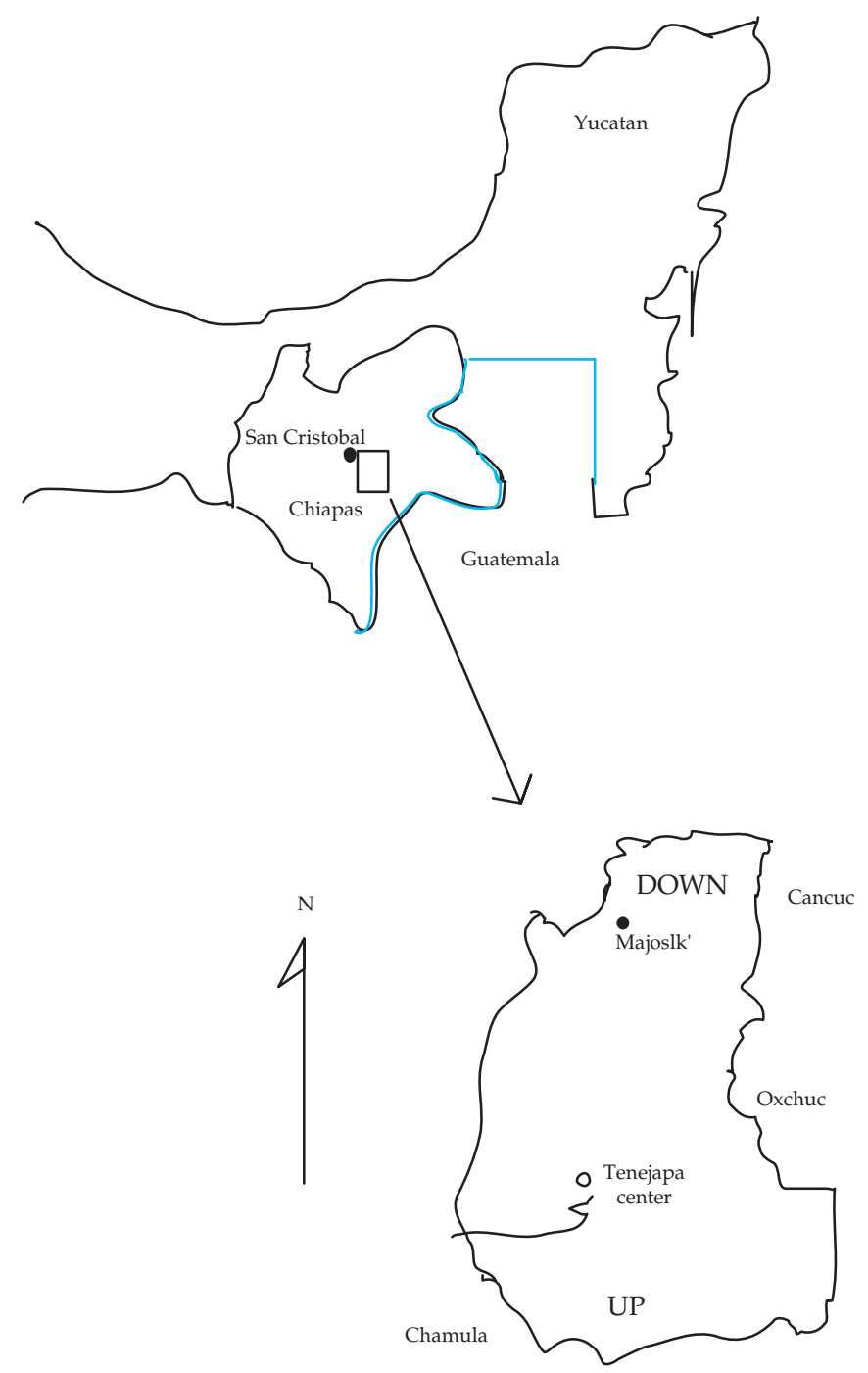

Figure 7.1 The geographical setting of Tenejapan Tzeltal

both after verbs of motion for expressing movement into or out of places, and after stative predicates for expressing static locations. The preposition $t a$ is thus semantically general over spatial concepts such as AT, IN, ON, TO, FROM, ABOVE, BELOW, etc. The semantic load for indicating a particular spatial relation is therefore carried in nouns and verbs, for each of which there is a relatively small set of roots in Tzeltal (on the order of 3,000 for both), with a highly productive morphology for deriving noun and verb stems from them. 
The basic structure of the maximal noun phrase is given in (1) (word order in the phrase is fixed): ${ }^{4}$

$$
\begin{aligned}
& (\text { determiner })+(\text { quant. })+(\text { adj. })+\text { Noun }_{\text {head }}+(\text { plural })+(\text { clitic }) \\
& \text { te cheb pukuj ach'ix -etik -e } \\
& \text { ART two wicked girl PL CL }
\end{aligned}
$$

A prepositional phrase with a possessed noun - an important resource for locative descriptions - has the structure in (2) (again with word order fixed):

$$
\begin{aligned}
& \left.\left.\mathrm{TA}+\text { Erg- }+ \text { Noun }_{\text {head }}+\text { (determiner }\right)+ \text { (Possessor }\right)+ \text { clitic } \\
& \text { ta } s \text { - na te winik } \\
& \text { PREP 3E house ART man CL }
\end{aligned}
$$

'at the man's house'

Minimally an NP can consist of just a noun, or just a quantifier, or just an adjective. This minimal NP can be turned into a predicate expressing a full proposition by suffixing an absolutive suffix, as in: antz-on 'I am a woman', luben-at 'you are tired', cheb-otik 'we are two (i.e. there are two of us)'. A stative form of a verb (consisting of a root plus an adjectival or a stative aspect suffix) with an absolutive suffix is a predicate of the same kind (e.g. tek'el-on, 'I am standing', chuk-bil-on 'I have been tied up').

Verbs as a class are distinguished by taking aspect marking. Finite verbs are either transitive (taking ergative prefixes and absolutive suffixes), ditransitive (taking ergative prefixes and the ditransitive suffix -be plus absolutive suffixes), or intransitive (all others, taking only absolutive suffixes). ${ }^{5}$ The basic structure

4 Tzeltal transcription conventions are based on a practical orthography; symbols correspond roughly to their English equivalents except that $j=\mathrm{h}, x=\mathrm{sh}$, and 'indicates a glottal stop or glottalization of the preceding consonant. Abbreviations for glosses are as follows: 1,2,3 E 1st, 2nd, 3rd person ergative prefixes (which mark both subjects of transitive verbs and noun possession), 1,2,3 A - the corresponding absolutive suffixes, 1PLE - 1st person plural exclusive, 1PLI - 1st person plural inclusive, PL - 2nd or 3rd person plural, DIST - distributive/plural, ASP neutral aspect, CMP - completive aspect prefix, CMPL - completed change of state suffix, ICP incompletive aspect prefix, ART - article, AUX - auxiliary verb, CJ - conjunction, CL - clitic, DEIC - deictic element, DEM - demonstrative, DIM - diminutive, DIR - directional, DIT ditransitive, EXIST - existential predicate, IMP - imperative, NAME - personal or place name, NC - numeral classifier, NEG - negative particle, PASS - passive, PPrt - passive participle, PREP - preposition, PT - particle, QUOT - quotative particle, REL - relational noun, STAT stative (perfect) aspect, SUBJ - subjunctive. A text identification preceding the Tzeltal examples indicates their source in naturally occurring events or interactional 'space games'; if unmarked they are from my field notes.

5 Verb roots belong to formal classes (Transitive, Intransitive, Positional, or Transitive/Positional $(\mathrm{T} / \mathrm{P})$ ) on the grounds of how they inflect without being further derived, but most verb roots can be derived to form a verb stem of changed valence. T/P is the biggest root class, and these fall on a cline (as shown by Haviland (1994a) for Tzotzil) depending on whether they take more transitive-type morphology or more positional-type morphology. 
of the transitive verb phrase is given in (3); the only obligatory elements are aspect marking, verb root and pronominal (ergative/absolutive) affixes.

(3)

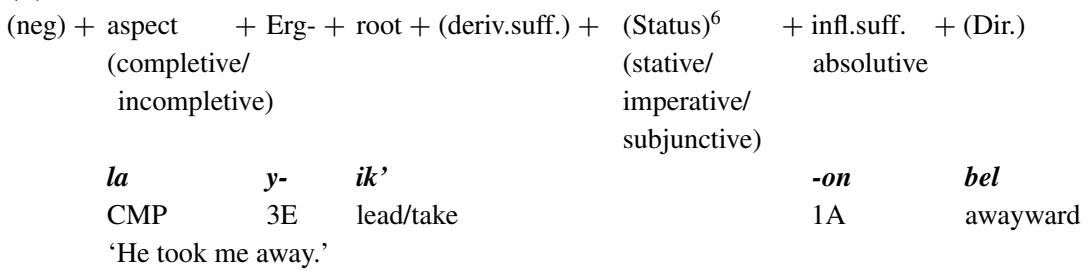

There is very little published material on Tzeltal grammar, unlike the situation for Tzeltal's closely related neighbour Tzotzil. A basic description of Tzeltal phonology and morphology is Kaufman 1971; for readers of French there is a introduction to the language which includes historical and sociolinguistic information as well as a grammatical sketch (Monod-Becquelin 1997; see also Polian 2004). The best (however, unpublished) dictionary is Berlin, Kaufman and Maffi 1990. Linguists working on Tzeltal grammar have to begin by extrapolating from the excellent descriptions of Tzotzil (e.g. Laughlin 1975, Haviland 1981, 1988, Aissen 1987), and then work out the specific grammatical details of Tzeltal for themselves. In partial compensation for this lack, there are some good semantic descriptions (Berlin 1968, Stross 1976). There are also some published Tzeltal texts (e.g. Stross 1977, 1978, 1979), as well as a huge corpus of published Tzotzil texts (e.g. Laughlin 1977, 1980, 1988). ${ }^{7}$

\subsubsection{Spatial language}

In Tzeltal, the generic way to ask where things are located is with the questionword banti, 'where', and the existential predicate ay, 'exist/be located':

$$
\text { banti ay- } \phi \text { te } y \text {-ach'il bojch-e? }
$$

where exist-3A ART 3E-new gourd-CL

'Where is the new gourd bowl?'

To ask where things are moving the same banti plus a motion verb is employed:

\footnotetext{
6 'Status' is a Mayan category, a slot in the verbal core where - in Tzeltal - perfective aspect and mood (imperative, subjunctive) are expressed.

7 A recent innovation in Mexico is the publication of texts in indigenous languages, for example in the series Cuentos y Relatos Indígenas published by the Universidad Nacional Autónoma de México, which includes some Tzeltal texts. Another series, published by the Sna Tz'ibojom, 'House of the Writer' includes the first native-speaker novel written in Tzeltal (Méndez Guzmán 1998). These texts are (to date) only available in Mexico, however.
} 


$$
\text { banti ya } x \text {-ba-at? }
$$

where ICP ASP-go-2A

'Where are you going?'

The linguistic resources Tzeltal offers for answering such questions with a spatial description are elaborate. Chief among them are the following:

i. existential locative expressions with ay

ii. deictics: demonstratives, adverbs, presentationals

iii. dispositional adjectives, often in combination with (iv) and (v)

iv. body-part relational noun locatives

v. absolute ('cardinal') directions

vi. motion verbs, directionals and auxiliaries

The first two are used in minimal locative descriptions, while the others constitute the core resources for specifying in detail the location, disposition, orientation or motion of a figure in relation to a ground.

\subsubsection{Location and existence}

The simplest locative description utilizes the existential predicate $a y^{8}$ with a prepositional phrase referring to a place:

$$
\begin{aligned}
& a y-\phi \quad t a \text { be te tz'i'-e } \\
& \text { EXIST-3A PREP path ART dog-CL } \\
& \text { 'The dog is on the path' }
\end{aligned}
$$

$$
\begin{array}{llll}
a y-\phi & \text { ta } & \text { tuxtla ya'tik jtatik } & \text { kunerol } \\
\text { EXIST-3A PREP Tuxtla today Mr. President }
\end{array}
$$

'The President is in Tuxtla today'

The ay in these examples indicates that the figure is 'coincident with' the ground, that their spatial regions overlap or coincide, but it provides no further information about the properties (either topological or path) of this relation. This ay construction is not, however, the canonical way to specify the location of previously mentioned things in the visible environs of speakers. One of its core uses is to introduce a new topic, as in the story-opener in $(8)$ :

$$
\begin{aligned}
& \text { ay- } \phi \quad \text { laj pulemal ta namej } \\
& \text { EXIST-3A QUOT flood PREP long_ago } \\
& \text { 'There was, it is said, a flood long ago' }
\end{aligned}
$$

It can also be used to describe an achieved change of location.

\footnotetext{
8 Technically, ay is not a verb, as it does not take aspect.
} 
'She is now at her house'

Beyond the range of visibility, however, it is used in a general locative sense, as in example (10) (from Smith n.d.: 18):
A: banti ay- $\phi$ te jnik-e? where EXIST-3A ART NAME-CL 'Where is Nik?'
B: $a y-\phi \quad$ ta $\quad k$ 'altik EXIST-3A PREP cornfield 'He's in (the) cornfield'

Ay is also used to specify location on the uphill/downhill coordinate; as we shall see, ajk'ol 'uphill' and alan 'downhill' are nouns specifying an abstract axis along which objects can be located:
A: banti ay- $\phi$ te limete-e? where EXIST-3A ART bottle-CL 'Where is the bottle?'
B: $a y-\phi \quad$ ta ajk'ol
EXIST-3A PREP uphill
'It's (towards) uphill'

And this is the way to describe the location of things at named places:

Q: 'Where is the doctor's office?'

A: ay- $\phi$ ta Jobel

'It is in San Cristóbal'

Thus, although ay can operate as a general-purpose locative, in practice it tends to be restricted to these particular kinds of contexts. In specifying the location of small movable objects, Tzeltal speakers generally prefer a different strategy - a 'multiverb' strategy in the terminology of Ameka and Levinson (forthcoming). In the topological book descriptions, the location of the figure in any of the seventy-one pictures could be grammatically described with ay. But ay was proffered as a possibility by one or more of three consultants in less than half of the cases. While it is possible to be unspecific about spatial relational information by using the existential $a y$, for most of these pictured spatial relations the preference is to be specific with a dispositional specification.

\subsubsection{Deictics and locative descriptions}

Deictic adverbials and demonstratives are another resource that can be used for locative descriptions when only a minimal specification is necessary. There 
Table 7.1 Deictics in Tzeltal

\begin{tabular}{llll}
\hline \hline & $\begin{array}{l}\text { PROXIMAL } \\
\text { (near speaker) }\end{array}$ & $\begin{array}{l}\text { DISTAL } \\
\text { (farther from speaker) }\end{array}$ & ANAPHORIC \\
\hline $\begin{array}{l}\text { ADVERBS } \\
\text { small-scale } \\
\text { large-scale }\end{array}$ & $l i$ ' $+-i$ 'here' & $\begin{array}{l}l \\
\text { ' }+-e \text { 'there' }\end{array}$ & tey $+a$ \\
DEMONSTRATIVES & $l i$ ' $+-i$ 'here' & lum + in-e 'over there' & \\
& $i n-+i$ 'this' & men- $+-e$ 'that' & men- $+-e$ \\
\hline \hline
\end{tabular}

are two sets of paired oppositions, one used in nearby (tabletop or in-reach space) and one for the larger scale. Both are binary oppositions (semantically 'proximal' and 'distal'), made up of two morphemes: an adverbial 'here'/'there' or a demonstrative 'this'/'that' term together with a terminal deictic clitic. A third adverbial term, tey, 'there', is primarily anaphoric; a locative question such as li' $i$ bal? '(Is it) here?' is almost invariably replied to (if it's affirmative) with tey, '(It's) there'). ${ }^{9}$ It is perfectly possible in Tzeltal to answer a Where-question simply by pointing, gesturing with hands or head, ${ }^{10}$ or using deictic adverbials or demonstratives, as in:

lum ay- $\phi \quad$ ine

there EXIST-3A there

'It's over there'

$$
\begin{aligned}
& l i \text { ' nax ay- } \phi \\
& \text { here just EXIST-3A } \\
& \text { 'It's just here' }
\end{aligned}
$$

These strategies alone, however, are not the preferred way to describe spatial locations and relations even within the interactants' visible local space (e.g. within a visible radius of, say, ten metres, or whatever the sociocentrically relevant space is in a given situation). One of the deictic adverbs ( $l i$ ' $i$, 'here', tey, 'there (anaphoric)', lum, 'over there') may accompany a dispositional locative phrase describing the location of something, but it relatively rarely stands alone to specify location. ${ }^{11}$ Paradoxically, it is in pointing out the locations of

9 See Brown 1991, Brown and Levinson in preparation, for more details on Tzeltal deictics.

10 Pointing is with index finger, thumb, or whole hand held flat, or with the whole head; I have not observed lip-pointing in this community.

11 This is not true for young children, who rely much more on deixis. One salient difference between the responses of five-year-old children and adults to our topological elicitation book is that the children respond to nearly every picture with ja' ini 'it's this one' (pointing to the yellow figure), whereas adults produce a fully specified proposition like: 'It (the dog) is sitting next to its house.' (The same has been observed for young English children, M. Bowerman, p.c.) 
distant objects and places that 'proximal' deictics and pointing often appear (suggesting that immediacy rather than proximity might be the appropriate semantic distinction). The natural response to a Where-question in these circumstances is to point in the direction of the queried place and say things like:

(15) (In answer to 'Where is the schoolhouse?', which lies about $1 / 2$ mile away)

li' nax ini

here just here

'It's just here'

(16) (In answer to 'Where is Tenejapa Centre?' at some 8 miles distant)

li' ay- $\phi-i$

here EXIST-3A-here

'Here it is'

(17) (In answer to 'Where is Mexico City?' at about 1,000 miles distant)

li' niwan ay- $\phi-i$

here perhaps EXIST-3A-here

'It's perhaps here'

A 'proximal' deictic expression ( $l i$ '- $i$, 'here', or $j a$ ' in- $i$ 'it's this') used to indicate distant objects seems to have a virtually obligatory accompaniment in the act of pointing, as if to indicate, 'Here, at the end of a line coming off the end of my finger, is the place you want to know about.' In no instances in our elicitation sessions did consultants use the distal/anaphoric deictic (tey 'there') in such contexts. If the place or object being pointed out is visible (as opposed to being projected into non-visible realms from a visible point on the horizon), a presentational expression often accompanies pointing:

in ta ba'ay- $\phi$

this at where-EXIST-3A

'There it is' (lit. 'this is where it-exists at')

These deictic strategies, along with ay and the use of a simple 'at [place name]' strategy, provide minimal spatial descriptions, giving no information about the nature of the figure and ground objects.

\subsection{Static location}

Static 'topological' relations of containment, contiguity and immediate adjacency, which in English are expressed by the prepositions in and on, (e.g. 'the apple is in the bowl', 'the picture is on the wall') are conveyed differently in 
Tzeltal. ${ }^{12}$ Crucially, there is only one preposition, the semantically neutral $t a$, which in its spatial uses could be glossed 'at'. Consequently, the precise spatial relation must be conveyed either by a nominal expression or by the predicate, or by a combination of these. The most idiomatic full locative description in Tzeltal is a locative clause combining a dispositional predicate with a prepositional phrase containing a noun with certain understood spatial properties:

$$
\begin{aligned}
& \text { DISPOSITIONAL ta Ground NP Figure NP } \\
& \text { waxal- } \phi \quad \text { ta lum p'in } \\
& \text { vertically_standing-3A AT ground pot } \\
& \text { '(The) pot (is) vertically-standing on the ground' }
\end{aligned}
$$

This is how the topological relations pictures were most frequently described, using one or both of these two sets (dispositional predicates, spatial nouns) of resources. An example from the 'Topological Relations Picture Series' book (TRPS; see Chapter 1, §1.4.1) illustrates how containment is expressed without an 'in' preposition:

$$
\begin{aligned}
& \text { tik'il ta bojch (mantzana). } \\
& \text { inserted_in PREP gourd-bowl (apple) } \\
& \text { 'It (the apple) is inserted-into the gourdbowl' (Picture 2) }
\end{aligned}
$$

Let us look at the nominal and verbal parts of this construction in turn.

\subsubsection{Body parts and relational nouns}

The ground NP may simply be named, as in (19) and (20). But a common way of specifying more precisely the location of the figure is to assign body parts to the ground and specify in (or near) what part of the ground the figure is to be found. The construction is as follows:

$$
\begin{array}{ll}
\text { 'at' } & \text { SUBREGION GROUND } \\
\text { ta } & \text { possessed body part noun phrase }
\end{array}
$$

For example:

$$
\text { ta s-jol witz }
$$

AT 3E-head mountain

'on the top of the mountain' (tree) (TRPS 65)

ta s-xujk s-na

AT 3E-side 3E-house

'by the side of its-house' (dog) [picture 6]

12 This section provides a summary of the resources for describing static spatial arrays in Tzeltal. For more details see Brown 1991, 1994, Levinson 1994, and Bohnemeyer and Brown forthcoming. 

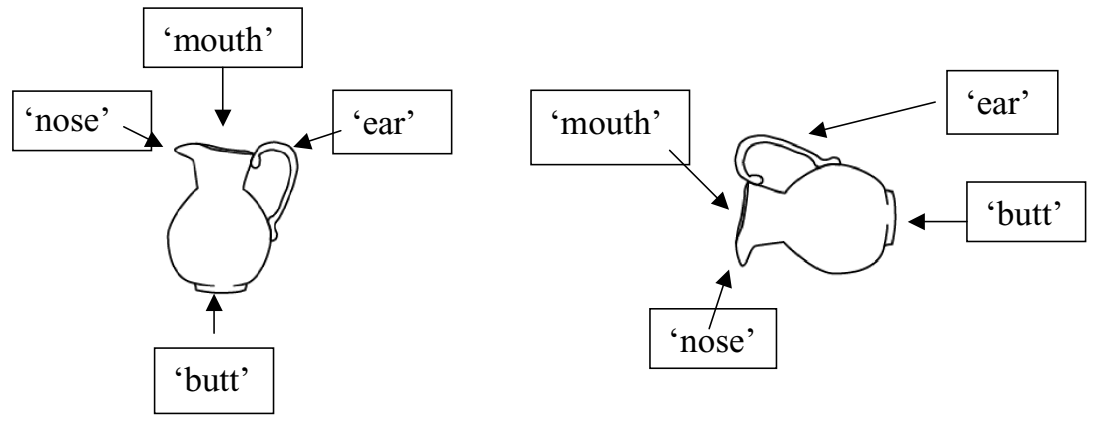

Figure 7.2 Object-centred geometry of Tzeltal body-part terms

$$
\begin{aligned}
& \text { pak'al- } \phi \quad \text { ta s-xujk sti'il } \quad \text { (timbre) } \\
& \text { stuck_onto-3A PREP 3E-side } 3 \text { 3E-edge (stamp) (TRPS 3) } \\
& \text { 'It (the stamp) is stuck onto its (the envelope's) edge' }
\end{aligned}
$$

In terms of figure and ground relations, the job of these body-part expressions is to further specify the ground (by imposing a 'body' structure on it) and to claim that the figure is 'coincident with' - at or immediately adjacent to - this named part of it. This topological or intrinsic system relies on object-internal axes to assign body parts; it is therefore sensitive to the orientation of the Ground object (although the whole array of figure/ground is orientation free, in the sense that it is not dependent on a larger spatial framework). Thus, unlike English on top of or underneath, a Tzeltal expression of relational position changes when the ground object rotates - consider a fly hovering above the jug in Figure 7.2, which would be described as now 'at it's mouth' (left panel) and now 'at it's ear' (right panel). The body parts exploited for this purpose in our corpus of locative descriptions are set out in Table 7.2. These are probably not a completely closed set; it would be possible to use other body-part terms in creatively locative phrases. These, however, are the ones routinely extended to inanimate objects on the basis of their spatial (mainly shape) properties. ${ }^{13}$ Of these only the last three, ne 'tail', ok 'base, trunk' and xujk 'side' have their primary reference to non-human body parts; the rest (and indeed, those most frequently used) refer equally to human or animal parts. ${ }^{14}$

All of these body parts (with the partial exception of pat and xujk; see below) are used to designate subparts of an object or of a person or animal's body

13 See Levinson 1994 for an analysis of the spatial algorithms underlying the allocation of body parts to inanimate ground objects in Tzeltal. See de León 1992, 1993 for the corresponding terms in Tzotzil.

14 This list compares with a potential list of some seventy-eight Tzeltal human body-part lexemes (Stross 1976). Thus only a small subset of the potential repertoire of body-part terms is routinely exploited for locative specifications. 
Table 7.2 Body-part locatives

\begin{tabular}{|c|c|c|c|}
\hline Root & & Possessed form & \\
\hline jol & 'head' & ta s-jol & 'at its head' \\
\hline pat & 'back' & ta s-pat & 'at its back' \\
\hline ch'ujt & 'stomach, belly' & tax-ch'ujt & 'at its belly' \\
\hline akan & 'foot' & ta $y$-akan & 'at its foot' \\
\hline$k^{\prime} a b$ & 'arm, hand, branch' & ta $s-k^{\prime} a b$ & 'at its hand/branch' \\
\hline it & 'butt, rump' & ta $y$-it & 'at its rump' \\
\hline$n i^{\prime}$ & 'nose' & ta $s-n i$ & 'at its nose' \\
\hline elaw & 'face' & ta y-elaw & 'at its face' \\
\hline sit & 'eyes, face' & ta s-sit & 'at its eyes/face' \\
\hline$t i^{\prime}$ & 'mouth, lips' & ta $s-t i^{\prime}(i l)$ & 'at its mouth/edge' \\
\hline chikin & ‘ear’ & ta $x$-chikin & 'at its ear/corner' \\
\hline$n u k^{\prime}$ & 'neck' & ta s-nuk' & 'at its neck' \\
\hline xujk & 'side, corner' & ta $(s)-x u j k$ & 'at its side' \\
\hline$o k$ & 'lower extremities, base, trunk' & ta $y$-ok & 'at its base' \\
\hline ne & 'tail' & tas-ne & 'at its tail' \\
\hline
\end{tabular}

and cannot be extended to indicate a region beyond the borders of the body. This is especially notable with respect to $k^{\prime} a b$, 'arm/hand', for as we shall see below, although a Tzeltal speaker can specify a body part more precisely as 'left arm/hand' (-xin k'ab) or 'right arm/hand' (s-wa'el k'ab) (and similarly for left/right leg/foot), these terms do not extend to the regions left and right, respectively, of the reference person. In this respect, the body-part terms contrast with the small closed set of relational nouns, which are also used, in their possessed forms, in a precisely analogous fashion to body parts, to designate subregions of a ground.

$$
\text { p'ekel- } \phi \quad \text { ta } y \text {-anil xila te ala pelota-e }
$$
low_down-3A PREP 3E-underneath chair ART DIM ball-CL 'The little ball is low down underneath the chair' (TRPS 16)

$$
\text { tik'il- } \phi \quad \text { ta } \quad \text {-util bojch (mantzana) }
$$

inserted_in-3A PREP 3E-inside gourd (apple)

'It (apple) is inserted into the inside of the gourd bowl' (TRPS 2)

The complete Tzeltal set of relational nouns (as used in locative descriptions with preposition $t a$ ) is presented in Table 7.3. The set of relational nouns is both morphologically and semantically much more heterogeneous than the set of body-part nouns used in locatives. Three of the relational nouns in Table 7.3, $-b a,-e^{\prime} t a l$ and $-t z$ 'eel, can designate actual parts of inanimate objects, ${ }^{15}$ while

15 For example, - $b a$ and -e'tal can refer, respectively, to the uphill and downhill edges of a cornfield or patio; they can also refer to the vertically above-region and below-region of a stack of tortillas. 
Table 7.3 Relational noun locatives

\begin{tabular}{|c|c|}
\hline ta y-util & 'at its inside; inside it' \\
\hline ta y-anil & 'underneath it; in its enclosed underneath area; also 'downhillwards' of it' \\
\hline ta $s-b a$ & $\begin{array}{l}\text { 'at its top side or edge (vertically, e.g. of a table; or 'uphillwards', e.g. of a } \\
\text { cornfield)' }\end{array}$ \\
\hline ta y-e'tal & $\begin{array}{l}\text { 'at its bottom edge (vertically, e.g. bottom of a stack of tortillas, or downhillwards } \\
\text { edge of a field or patio)' }\end{array}$ \\
\hline ta y-ajk'ol & 'at its uphill side; above it' \\
\hline ta y-alan & 'at its downhill side, i.e. below it' (more colloquially, $y$-anil is used for this) \\
\hline ta s-tojol & 'straight ahead of it' \\
\hline ta $y$-olil & 'at its half $(=$ middle $)$ '; i.e. 'between' \\
\hline tas-tz'eel & 'at its side' (of a road, school, doorway, etc.) \\
\hline
\end{tabular}

the others designate regions defined in relation to objects (-util, -anil, -olil), in relation to cardinal directions ( $a j k^{\prime}$ 'ol and alan), or in relation to an animate observer's direction of gaze (-tojol). The last, -tz'eel, 'on its side/edge' (from the P root $t z$ 'e, 'be on (its) side'), is interesting because it does double-duty in locative expressions. As mentioned above, in its dispositional (adjectival) form $t z$ 'eel expresses the position of a figure object 'lying on its side':

$$
\begin{aligned}
& \text { tz'eel- } \phi \quad t a \text { lum te mexa-e } \\
& \text { on_its_side-3A PREP ground ART table-CL } \\
& \text { 'The table is lying on its side on the ground' }
\end{aligned}
$$

But $t z$ 'eel can also be a relational noun designating 'to the side of', i.e. a region of the ground:

$$
\begin{aligned}
& \text { tekel- } \phi \quad \text { ta s-tz'eel eskwela te' } \\
& \text { standing-3A at 3E-side school tree } \\
& \text { 'The tree is standing at the side of the school' }
\end{aligned}
$$

In this respect it is like the positionals kajal and k'atal (discussed below), which can also function both as dispositionals ('positioned-on-top-of' and 'acrossways-positioned', respectively) and as nouns (meaning 'the top or uphill side' and 'the crossways direction', respectively).

Although very similar in both syntax and function to the body parts, relational nouns are distinguishable from them by both semantic and formal criteria. Body parts form a clear formal class (though not all body-part terms in this class are exploited for spatial description). In contrast, relational nouns are not (at least synchronically) body-part terms. Instead, they come from nouns designating directions (alan, ajk'ol), regions ( $e^{\prime} t a l, b a$, olil, util, anil), or from verb roots ( $\left.t z^{\prime} e e l\right)$ or adjective roots (tojol from the root $t o j$, 'straight'). Despite these heterogeneous sources, they have all become partly grammaticalized, to different degrees, as relational nouns which enter into locative constructions analogously 
to body-part terms, presumably because some aspect of their original meaning was relevant for describing spatial regions. For a few of these relational nouns grammaticalization has proceeded far enough to make the possessive prefix optional, as in example (29) where $b a$ 'top' is not possessed. ${ }^{16}$

$$
\begin{aligned}
& \text { pachal- } \phi \quad t a \quad \text { ba mexa te ala baso } \\
& \text { bowl_shaped_sitting-3A PREP top table ART DIM cup } \\
& \text { 'The little cup is sitting on the top of the table' (TRPS 1) }
\end{aligned}
$$

Semantically, unlike the body-part terms, the relational nouns designate subregions which are generally around or adjacent to the ground in question, designating a search space for the object within a few inches, or perhaps a few feet, of the ground. (The non-possessed use of ajk'ol and alan, by contrast, does designate indeterminately extending regions in the uphill and downhill directions, respectively, as we shall see.) The body-part terms pat and $x u j k$, in so far as they can be used to designate regions rather than parts of a body, are perhaps intermediate between body-part terms and relational nouns. ${ }^{17}$

Body-part terms and relational nouns are a core resource for the Tzeltal intrinsic system, a system which is 'orientation free' and indifferent to point of view of speakers. There are, however, some marginal deictic uses of body-part and relational noun locatives. One is in the trivial sense that, as in any intrinsic system, the ground may be deictic - the body part may be that of the speaker and/or addressee (it's 'at my face'/ 'at your back'/'at our-inclusive middle' (i.e. between us)'). A second entry point for an egocentric viewpoint is found in certain cases where a body part is used, not - as it normally is in locative expressions - as an intrinsic part of the relatum immediately adjacent to which the figure is located, but with the speaker as deictic origo, analogous to English in back of in the relative frame of reference. This relative anchoring is largely restricted to describing things in relation to ground objects which are symmetrical in the horizontal dimension (having no obvious front/back orientation) 'non-featured objects' as they are labelled in the psychological literature. So, for example, instead of ta s-pat meaning 'at its intrinsic backside' (its normal usage in Tzeltal), it can be used to mean 'behind it, from my viewpoint'. Two body-part terms, pat and xujk, lend themselves to this kind of usage; for example, ta s-pat na can mean either at the house's intrinsic front (as defined by the

16 See de León 1992 on grammaticalization of the corresponding relational terms in Tzotzil.

17 There is one further possessed noun with a spatial meaning, indeed perhaps the quintessential spatial meaning: $y$-awil, meaning 'its-allocated place or space', as in $y$-awil na 'the place planned for a house to be built', $y$-awil k'altik 'the area set aside for planting a new cornfield'. It can also be used in the general sense of 'room, space', as in: ma'yuk y-awil 'There's no room' (for objects or persons to fit into a relevant area). In its unpossessed form (awilal), it can mean 'property', 'fireplace' or 'dishes'! (Berlin, Kaufman and Maffi 1990). The possessed form, $y$ awil, however, is not used as a possessed part term (to mean something like 'its space, as part of a larger whole'), and it does not enter into locative descriptions like the ones described here. 
doorway) or at its relative back, on the side away from where the speaker is. Similarly, ta s-xujk pojp 'at the bag's side' is defined in relation to the speaker's location: as a pojp bag (a straw matting bag sewn into a large cylinder shape) has no intrinsic front, back or sides, ta s-xujk can be defined as 'to the side of it' from the point of view of the speaker, i.e. not in front or behind. (See de León 1992, 1993 for comparable data from Tzotzil.)

The relational noun -tojol 'straight ahead of' has the same kind of relative uses. A possessed form of -tojol is generally used to describe a figure object located in the direct unobstructed line of gaze of the possessor, which may be a deictic ground (when first or second person possessed), or a third party (when third person possessed). There is a relative usage of s-tojol, however, with inanimate grounds, a usage which is precisely comparable with the deictic use of 'in front of' in English: just when the relatum is an object without a face (e.g. a tree or post), so that one could not construe ta s-tojol as meaning 'straight ahead of its face', ta s-tojol can specify a deictically assigned angle from the speaker's point of view (e.g. ta stojol te' can mean 'in front of the tree' in the sense of 'in the speaker's direct line of gaze, between speaker and tree, but closer to the tree').

These relative usages of body-part terms and the relational noun -tojol exist at the margins of what is essentially an intrinsic system of spatial reckoning. There is no systematic set of oppositions - no relative 'front' to oppose to 'back' and no relative 'left'/'right' usage, and hence no full-blown front/back/left/right relative system.

The prepositional phrase with a body-part or relational noun is one element in a fully specified Tzeltal locative expression. A second crucial element is the predicate, characteristically constituted by a dispositional adjective.

\subsubsection{Dispositionals}

Tzeltal, like other Mayan languages, has several hundred dispositional roots with highly specific meanings conveying shape, configuration, orientation, size, angle and other spatial properties. ${ }^{18}$ These (and to a lesser extent) other stative predicates carry an important functional load in locative descriptions. Unlike the sit/stand/lie/hang positionals in some languages, ${ }^{19}$ Tzeltal dispositionals are not used in existential propositions; nor are they grammatically obligatory in locatives. However, with only one semantically vacuous preposition, some relational information - about exactly how the figure is configured in relation to the ground - is usually carried in the predicate, which in a static location

18 There is a root class of positionals, but stative adjectives in $-V l$ are formed not just from positional (P) roots, but from some transitive (T) and 'transitive/positional (T/P) roots as well. See Brown 1994, Bohnemeyer and Brown forthcoming; see also Haviland 1994 for Tzotzil.

19 See the descriptions of Dutch, Rossel and Arrernte, this volume. 
description is usually a stative adjective. For this, the class of dispositionals provides a large and ready source.

Some examples from our topological elicitation include:

kajal- $\phi \quad$ ta $s$-ba na (te winik-e)

mounted_on-3A PREP 3E-top house (ART-man-CL)

'He is on top of the house' (the man) (TRPS 34)

$$
\begin{aligned}
& k \text { 'atal- } \phi \text { jelawel ta mantzana (te te'-e) } \\
& \text { across-3A crossDIR PREP apple (ART stick-CL) }
\end{aligned}
$$

'It is crossways acrosswards through the apple' (the arrow) (TRPS 30)

tik'il- $\phi \quad$ ta $y$-util bojch (mantzana)

inserted-3A PREP 3E-inside gourd_bowl (apple)

'It is inserted in the inside of the bowl' (apple)' (TRPS 2)

jok'ol- $\phi \quad$ ta $\quad x$-ch'ujt pajk' te s-lok'omba antz hanging-3A PREP 3E-belly wall ART 3E-picture woman

'The picture of the woman is hanging on the wall's belly' (TRPS 44)

In other cases the position/shape/orientation of the figure is exactly conveyed by the dispositional predicate, while the precise spatial relation (whether IN or $\mathrm{ON}$, for example) is left to pragmatic interpretation.

$$
\begin{aligned}
& \text { pachal- } \phi \quad \text { ta setz' (baso) } \\
& \text { bowl_sitting-3A PREP plate cup } \\
& \text { 'It (the cup) is sitting at (i.e. on) the plate' (TRPS 1) }
\end{aligned}
$$

For many dispositionals the shape/configuration information in the predicate can apply to either the figure or the ground; compare (34) above with (35):

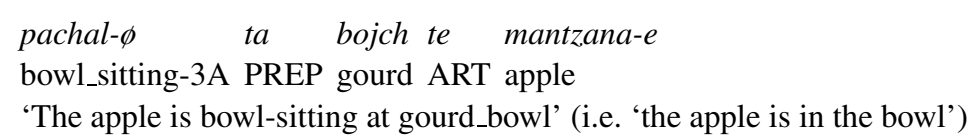

Such examples show that often it is the combination of predicate plus NP that conveys the spatial relation, not one or the other alone (see Brown 1994). Yet in other cases (e.g., (26) above) the same spatial relation is redundantly conveyed by each of these parts.

The hypertrophy of spatial meanings in dispositionals is amply illustrated by derived stative adjectives describing different body positions. These tend to have prototypical uses for specific classes of objects, humans or animals; some can, however, be extended to other categories if the people/animals/objects are appropriately positioned, and this is largely a matter of having the relevant body part or parts which can be taken as having been placed in the appropriate position/orientation. Table 7.4 lists some of the core dispositionals for taking 
various body positions. Any one of these, used in a locative expression, would indicate the figure as being body-positioned or oriented in the way stated AT a ground; depending on the ground object this would then be interpreted as the figure being ON, or IN, UNDER, or BESIDE the ground object. ${ }^{20}$ Dispositional and other adjectival predicates are not the only forms used to describe some of the topological pictures. In many cases a more active form is used, for example the passive participle form (PPrt) of a transitive verb indicating a stative situation resulting from an action:

$$
\begin{aligned}
& \text { tz'ap-bil- } \phi \quad \text { ta y-olil te ala mantzana } \\
& \text { pierce-PPrt-3A PREP 3A-middle ART DIM apple } \\
& \text { 'it (stick) having been pierced through the middle of the apple' } \\
& \text { (TRPS 70) }
\end{aligned}
$$

Often it is possible to choose freely between a static and more active perspective on the scene by using either a stative adjective (with $-V l$ ) or a passive participle (with -bil), as in:

$$
\begin{aligned}
& \text { chuk-ul- } \phi \text { / chuk-bil- } \phi \text { ta } x \text {-ch'ujt kantela (ala xela) } \\
& \text { tie-Vl-3A / tie-PPrt-3A PREP 3A-belly candle (DIM ribbon) } \\
& \text { 'It (ribbon) tied/having been tied around candle' (TRPS 4) }
\end{aligned}
$$

In fact, descriptions of topological spatial relations seem to fall onto an active/stative continuum, depending on (1) the kind of scene and (2) the perspective the speaker chooses to take on the scene. At the stative end of the continuum (and most locative-like) are construals of a configuration as a state, with the $-V l($ vowel $+/ l /)$ adjectival suffix. Somewhat more active, though still towards the stative end, are construals of a configuration resulting from someone's action (as in (36) and (37), with the passive participle suffix -bil). At the active end are construals in terms of an actor acting (e.g. in response to 'Where's the hat?', xpixjolinej ta sjol 'he has made it a hat on his head') or of stative (perfect) verbal forms (with-em or -oj, e.g. och-em, 'it has entered'). ${ }^{21}$ Indeed, many pictures can be naturally described with more than one of these possibilities, which are diagrammed in Figure 7.3. Together, the predicate (usually a dispositional adjective) and the prepositional phrase (formed with a body-part or relational noun) achieve the specification of where a figure object is and how it is positioned or configured in relation to a ground. Such a specification is often very detailed about the spatial properties of the figure and/or ground; given this specificity, the spatial relation between them is often left to inference.

20 See Haviland 1992 for the Tzotzil equivalents of these.

21 Although not strictly speaking locatives, from a Tzeltal point of view these descriptions carry explicit locational information - you know, for example, if someone has 'be-hatted himself' (s-pixjol-in-ej) by making a hat of something, that it is on his head. Similarly, something which is och-em 'having-entered' is now inside of the object it entered. 
Table 7.4 Dispositionals of body position

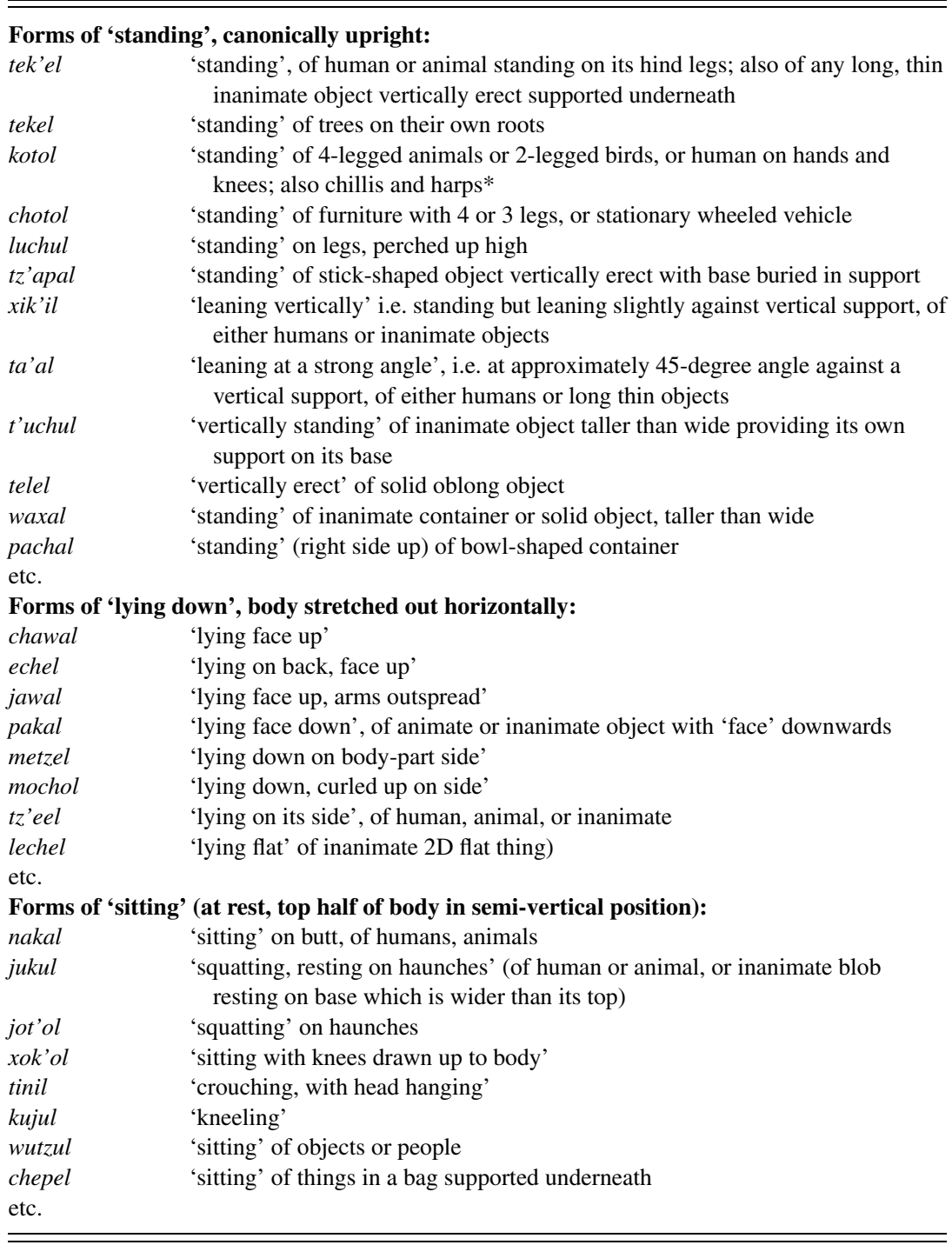

* Chillis 'stand' like animals despite not having any 'legs'; they are also 'eaten' with the verb for eating meat $(t i$ '). This illustrates the cultural embeddedness of the shape and position assessments underlying the use of these spatial terms. 


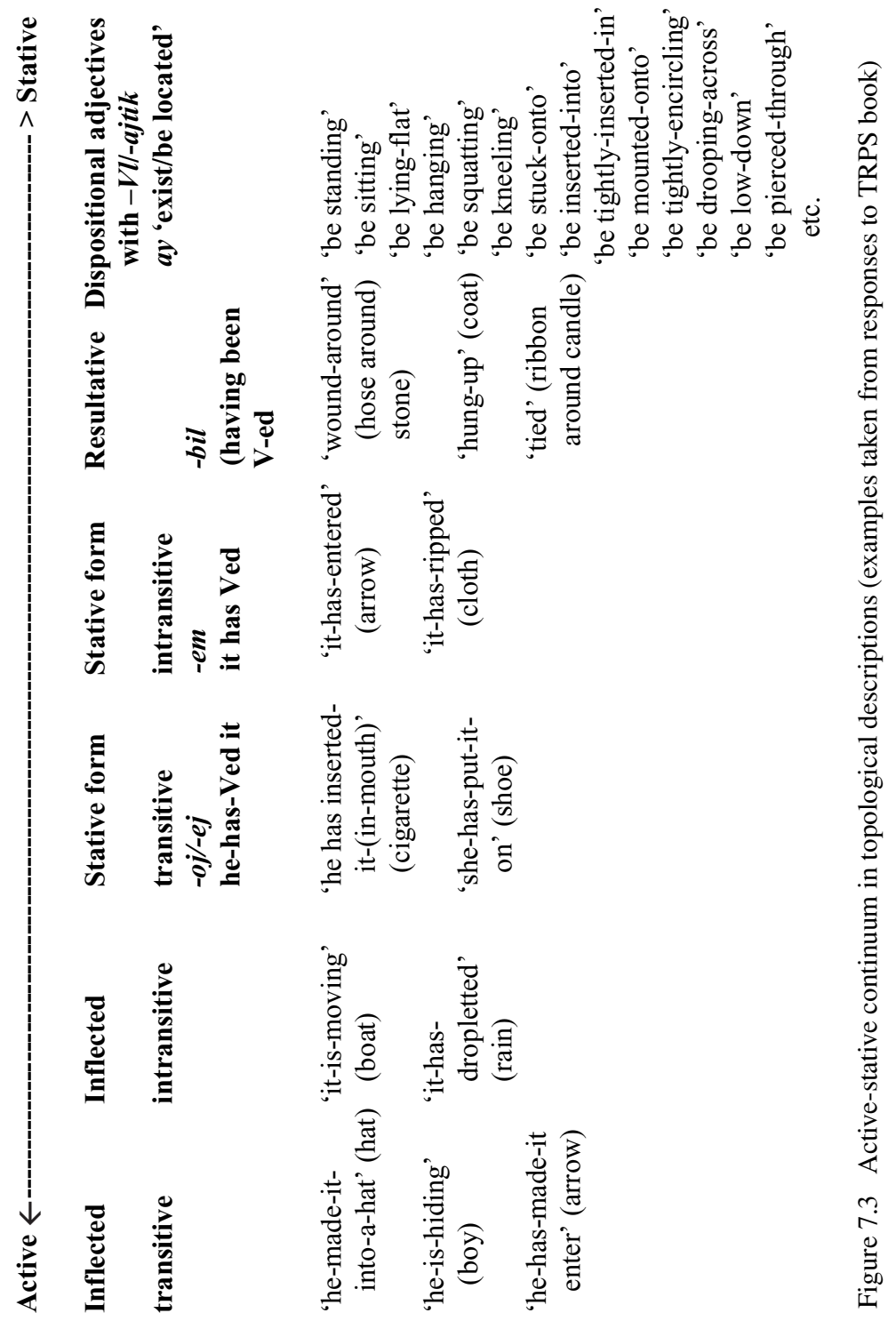




\subsection{Motion}

As we have seen, the Tzeltal positional roots, whether derived as adjectives or in their verb forms, are fundamentally about stasis, about location, position, configuration at a moment frozen in time. When it comes to describing movement, another set of verbs - motion verbs and their derived directionals are brought into play. Typologically, Tzeltal has features of both verb-framed and satellite-framed languages (Talmy 1983). The basic motion verbs encode pure Motion+Path analogously to verb-framed languages. But the directionals provide adverbial modifications which are satellite-like in contributing separate path information which can be added to the meaning of a predicate of any form. There are relatively few manner of motion roots (although manners of motion can be indicated by derivational machinery, e.g. reduplication), and in this respect Tzeltal is like most verb-framed languages.

Haviland (1991, 1993b) has produced a very thorough description of the corresponding motion verbs in the closely related Mayan language Tzotzil; analysis of Tzeltal suggests that motion description in these two languages is very similar indeed.

\subsubsection{Motion verbs, directionals and auxiliaries}

Motion verbs are prominent among the words derived from the very few intransitive roots (around 40) in Tzeltal (and in Tzotzil; see Laughlin 1975). There is a closed-class set of roots for describing motion path and incipience/termination; most of them can combine with a causative suffix to describe the corresponding caused motion. ${ }^{22}$ These intransitive verbs in Table 7.5 and their derived directionals are among the most frequent words in Tzeltal. These same motion roots are also the ones which can be used as auxiliaries before an inflected verb:

$$
\begin{aligned}
& \text { ya } \quad x-b a \quad k \text {-il- } \phi \quad k \text {-ala wakax } \\
& \text { ICP ASP-AUX(go) 1E-see-3A 1E-DIM bull } \\
& \text { 'I'm going to see my bull' } \\
& \text { ya } x \text {-jul } y \text {-al-be-t pajel } \\
& \text { ICP ASP-AUX(arrive.here) 3E-tell-DIT-2A tomorrow } \\
& \text { 'He'll arrive to tell you tomorrow' }
\end{aligned}
$$

As in Tzotzil (Haviland 1991: 6), the auxiliary plus main verb form a tightly bound constituent with the aspect marked on the auxiliary and not on the main verb, and with the person-marking only on the main verb. Also, as in Tzotzil, the primary reading of a Tzeltal motion auxiliary is 'move for the purpose of

22 The exceptions are tal 'come', $x k$ 'otok 'go and return' and laj 'finish', which cannot causativize, probably because other verbs pre-empt the causative meaning (e.g. jijtzes tal 'make it come closer', ju'tes 'finish it'). 
Table 7.5 Tzeltal motion roots

\begin{tabular}{ll}
\hline \hline ba & 'to go' \\
tal & 'to come, to arrive here' \\
'ot & 'to arrive there' \\
jul & 'to arrive here, return here' \\
och & 'to enter' \\
lok' & 'to exit' \\
mo & 'to ascend' \\
ko & 'to descend' \\
jil & 'to remain' \\
sujt & 'to return' \\
$k$ 'ax & 'to pass by somewhere and leave' \\
jelaw & 'to cross over' \\
sol & 'to pass by, go from A to B' \\
lijk & 'to begin' \\
jajch & 'to begin, to arise (e.g. get up in the morning)' \\
laj & 'to finish' \\
\hline \hline
\end{tabular}

doing V'. However, unlike in Tzotzil, no elements except person inflection not even aspectual clitics or particles - seem to be able to separate the two verbal elements (AUX + VERB) in Tzeltal.

Directionals are formed from the same set of roots, with a $-V l$ (vowel followed by $/ l /$ ) suffix that transforms them into deverbal directional particles; these immediately follow the inflected verb and indicate the direction or trajectory of the action specified in the verb. Directionals are the forms of the motion verbs that are the most multifunctional from the point of view of spatial description, being usable in both motion and static descriptions. By far the most frequent are tal 'coming' and bel 'going', but (with one exception) all of the motion verbs in this set have corresponding directionals.

lok'-an tal

exit-IMP comeDIR

'Come out (of the house, to here where I am)'

lok'-an bel

exit-IMP goDIR

'Go out (of the house, where I am)'

$$
\text { ya } x \text {-toy- } \phi \quad \text { moel likawal }
$$

ICP ASP-rise-3A ascendDIR sparrow_hawk

'The sparrow hawk flies far upwards'

$$
\begin{aligned}
& \text { ya s-bik'- } \phi \quad \text { koel chan te mut-e } \\
& \text { ICP 3E-swallow-3A descendDIR bug ART chicken-CL } \\
& \text { 'The chicken swallows down a bug' }
\end{aligned}
$$


ya j-tij- $\phi \quad$ lok'el te mut ta y-ut na

ICP 1E-send-3A exitDIR ART chicken PREP 3E-inside house

'I chase out the chicken from inside the house'

ya j-tij- $\phi \quad$ ochel xawin ta y-ut na

ICP 1E-send-3A enterDIR cat PREP 3E-inside house

'I chase (the) cat into the house'

ya $x$-tal $k$-ik'-at sujtel pajel

ICP ASP-come 1E-fetch-2A returnDIR tomorrow

'I'll come fetch you back (i.e., returning) tomorrow'

ya $x$-ben- $\phi \quad$ jelawel mut ta ch'ajan tak'in

ICP ASP-walk-3A crossDIR bird PREP cord metal

'The bird walks across (the patio, along) the electricity wire'

Alone among the directionals, moel and koel can also be placed before the verb, or after the preposition ta, as in moel a bajt ('up he went'); bajt ta moel ('He went up'), koel ya xbenotik ('We're walking down').

The set of motion verbs in Table 7.5, with their associated auxiliaries and directionals, forms a closed subclass of intransitive verbs in Tzeltal. There are a few other intransitive roots for specific kinds (or Manners) of motion, for example, been 'to walk/move along', animaj 'to run', an 'to flee', wil 'to jump, to fly', nux 'to swim', t'uxaj 'to fall'. These, however, do not form adverbial directionals or auxiliaries. ${ }^{23}$ There is also the possibility to derive verbs of motion from positional or other spatially rich roots, for example joyin-ta 'move in a circle around (it)', or toj-liy 'move straight towards (it)'. These and the manner-of-motion verbs are often followed by a directional - derived from the above-listed core motion verbs - indicating the direction of movement.

Haviland (1991) distinguishes five notional subclasses of Tzotzil motion roots on the basis of the kinds of paths they describe. The Tzeltal motion roots, although not always cognate, are very similar in their basic semantics as well as in the way they extend to temporal and aspectual meanings (for diagrams of the relevant paths see Figure 7.4). Slotting the Tzeltal forms into Haviland's five categories, we come up with the following classification. (Examples are drawn from a conversation where a woman is explaining her chronic sickness in terms of her husband's chronic infidelities. The motion verbs, auxiliaries and directionals under discussion are underlined.)

1 Deictically anchored motion: $\boldsymbol{b a}, \boldsymbol{t a l}, \boldsymbol{k} \boldsymbol{\prime}(\boldsymbol{t}), \boldsymbol{j u l}$ Here, as in Tzotzil (Haviland 1991: 7), there are two contrasts: motion towards a deictic centre

23 The one apparent exception, animaj 'run', is morphologically derived into an adverb before it can be used adverbially: ya xba animal kil, xon tz'in, 'I'll just go run and see, I said then.' 
'here' vs. motion away from 'here', ${ }^{24}$ and motion emphasizing arrival at a goal vs. setting out towards a goal. For example:

$$
\text { ya } x \text {-bajt- } \phi \quad \text { ta Yochib, ya } x \text {-yakub- } \phi \quad \underline{\text { tal }}
$$

ICP ASP-go-3A PREP PLACE, ICP ASP-get_drunk-3A comeDIR 'He goes to Yochib, he comes back drunk'

$\phi \quad$ bajt-ik s-tukel-ik. ma'yuk $x$-tal-uk

CMP go-3A_PL 3E-self-PL NEG ASP-come-SUBJ

ik'-ot-ok lejrol

fetch-PASS-SUBJ messenger

'They went (to town) by themselves. The messenger didn't come (here) to fetch them'

$$
\text { ya } x \text {-jul } j \text {-we'- } \phi \quad \text { waj, } k \text {-uch'- } \phi \quad \text { matz' }
$$

ICP ASP-arrive 1E-eat-3A tortillas, 1E-drink-3A corngruel

'I'd arrive (here) and eat tortillas, drink corngruel'

$$
\text { ay- } \phi \quad l a j \quad x-k^{\prime} o \quad s-l e^{\prime}-\phi \quad \text { ta Ch'ajkomaj, }
$$

EXIST-3A QUOT ASP-arrive 3E-search_for-3A PREP PLACE

'He would arrive (there) at Ch'ajkomaj looking for her,

$\begin{array}{lllll}a y-\phi & l a j & x-k^{\prime} o & s-l e^{\prime}-\phi & l u m \\ \text { EXIST-3A } & \text { QUOT } & \text { ASP-arrive } & \text { 3E-search_for-3A far_away } \\ t a & \text { Kulak'tik } & \\ \text { PREP } & \text { PLACE }\end{array}$

he would arrive (there) looking way over in Kulak'tik

te y-inam-e, k'o- $\phi$ tey ta s-le'el

ART 3E-wife-CL, arrive-3A there PREP 3E-search-DN

te $y$-inam

ART 3E-wife

for his (other) wife, he'd arrive there in the search for his wife'

$\phi \quad$ ba-on tz'in, $\phi \quad$ k'o-on tey a,

CMP go-1A PT, CMP arrive-1A there DEIC,

$\phi \quad k$ 'o s-k'opon- $\phi$ te j-mamal alib-e

CMP arrive 3E-talk_with-3A ART father_in_law-CL

'So I'd go, I'd arrive there, arrive to talk with my father-in-law'

${ }^{24}$ For ba/tal 'go'/'come' it is possible that 'go' is not deictic, but simply unspecified and acquires a deictic interpretation in contrast to 'come' (Wilkins and Hill 1995); I do not, however, think that this is the case for the corresponding directionals. This issue requires further research to establish whether the semantics of the directional ' $\mathrm{go}$ ' has possibly diverged from that of the motion verb 'go' in this instance. There may well be differences in the semantics of go/come across speakers, as Danziger (1998) found for the Mopan Maya. 
2 Point-oriented motion: $k^{\prime} a x$, sujt, jil, xk'otok, xtaluk, jelaw, sol Here the distinctions have to do with different sorts of trajectories in relation to an established reference point (which does not have to be the deictic origo), as in:

$$
\phi \quad k^{\prime} a x-\phi \quad l a j \quad y \text {-ik'- } \phi \quad \text { te antz-e }
$$

CMP pass_by-3A QUOT 3E-fetch-3A ART woman-CL

'He passed by, he said, to fetch the woman'

$$
\begin{aligned}
& \text { ya laj } x \text {-k'ax } y \text {-il- } \phi \quad \text { te alal-e, } \\
& \text { ICP QUOT ASP-pass_by 3E-see-3A ART child-CL, } \\
& \text { 'He'd come by he said to see the children, } \\
& \text { ya laj } x \text {-k'ax } y \text {-il- } \phi \quad y \text {-ala na } \\
& \text { ICP QUOT ASP-pass_by 3E-see-3A 3E-DIM house } \\
& \text { he'd come by to see his house' }
\end{aligned}
$$

(i.e. referring to her husband who had taken another wife and moved away, but returned (here) to see his children by the speaker).

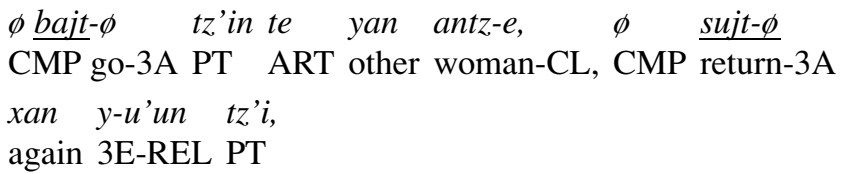

'The other woman went away, she returned (to her natal home) then'

la s-tikun- $\phi$ sujtel

CMP 3E-send-3A returnDIR

'He sent her back (to her parents, where she came from)'

$$
\text { melel la y-al- } \phi \quad \text { tal tz'in te kunerol }
$$

truly CMP 3E-tell-3A comeDIR PT ART president

"Really," the President told me (lit. said towards me)

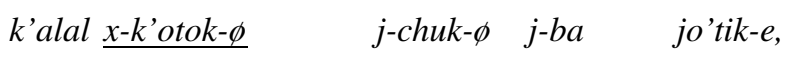
when ASP-go_return-3A 1E-tie-3A 1E-REFL 1PIEx-CL when we had gone and returned from our court case,

$$
\text { s-pisil te bi laj ay- } \phi \quad a^{\prime} w \text {-u'un-e, }
$$

3E-everything ART what QUOT EXIST-3A 2E-REL-CL, "everything that is said to be yours,

ja' me ya a'w-ich'- $\phi$ jilel sok te

it_is DUB ICP 2E-receive-3A remainDIR with ART

alal-etik $x i$

child-PL 3E-said

you should keep it (lit. receive it remaining) along with the children," he said.' 
Haviland's (1991: 9) description of the distinctions among these point-oriented motion verbs in Tzotzil is apt for the Tzeltal ones as well. Adapting his description to the Tzeltal facts: sujt adopts the reference point as a goal and presupposes that the trajectory left the same point earlier (so that the current goal represents a 'return'), as in (55). Jil suggests staying on at the reference point, presupposing that one is already there, as in (56). $K$ ' $a x$ suggests a trajectory through the reference point, but with motion that starts and finishes somewhere else ((53)-(54)). X-k'ot-ok means 'to have been in a place [from the perspective of no longer being there]' as in (56); with this verb the place where the protagonist is now, having once been somewhere else, is not limited to a deictic 'here' nor to a 'home base' (see also Dürr 1991). ${ }^{25}$ Tzeltal also has a morphologically analogous form meaning the opposite of $x k$ 'otok: $x$-tal-uk 'to have come and gone away again'. The three roots k'ax, jelaw and sol, have in common that they indicate motion through a reference point with beginning and end points unspecified. They contrast in that jelaw requires crossing a boundary, but what the precise semantic difference is between $k^{\prime} a x$ and sol is at present unclear (incidentally, $k^{\prime} a x$ can only be used as an auxiliary or main verb; the corresponding directional form is jelawel). ${ }^{26}$

3 Region- or enclosure-oriented motion: och, lok' Here what is at issue is the notion of a bounded region into which or out of which motion occurs. The region may be physically bounded (like a house or corral) or abstract (like a cooperative organization or political party). For example:

$$
\text { bi laj y-u'un ma a lok'-on bel, ... }
$$

Q QUOT 3E-REL NEG CMP exit-1A goDIR

“"why," he said, "didn't I leave (home) (lit. exit awaywards)

ja' nax a lok'- $\phi \quad \underline{\text { bel }}$ s-tukel te antz-e

it_is just CMP exit-3A goDIR 3E-self ART woman-CL

it was just the (other) woman alone who left (home)",

ja' jich a och- $\phi \quad$ tal te j-chamel-e

it is thus CMP enter-3A comeDIR ART 1E-sickness-CL

'That's how my sickness entered into me'

25 Tzeltal lacks a unique root analogous to Tzotzil 'ay, 'go and return'; instead it borrows the root $k$ 'ot from the deictically anchored set, which with an aspectual $x$ - and subjunctive -ok, means just what Tzotzil 'ay means: 'having gone and returned from somewhere'. In Tzeltal, $x k$ 'otok can be used as an auxiliary and as a main verb, but there is no corresponding directional.

${ }^{26} K^{\prime}$ 'ax means to go past some reference point and keep going (e.g. you may ' $k$ ' $a x$ ' by particular places while shopping); sol is much more restricted, used, for example, for crossing from one place to another place, both unspecified (solan ta wayel 'cross over to sleep', e.g. across the open space between kitchen and sleeping house), or for passing someone on the trail (solokon ta 'xujk a 'I'm passing you', e.g. from a place behind to a place in front of the other person on the trail). 
In fact Tzeltal och can also be used aspectually in the sense of entering into or beginning an action:

$$
\begin{aligned}
& \text { jich } \phi \quad \text { och-on ta poxta-el } \\
& \text { thus CMP enter-1A PREP medicate-DN } \\
& \text { 'Thus I began to be medicated' }
\end{aligned}
$$

Both och and lok' very often co-occur with the deictic directionals tal and bel (as in (57) and (58)), which add a deictic direction to their motion into or out of a region or enclosure.

4 Vertical axis motion: mo, $k o$ Tzeltal $m o$ and $k o$ indicate motion up and down (respectively) along a vertical axis; they can apply equally felicitously to the axis defined by ajk'ol 'uphill' and alan 'downhill', which, as we shall see in Section 7.5 , is prototypically not vertical but slanting at a (roughly) 45-degree angle to the horizontal. They can also be used on the horizontal with an absolute orientation (roughly, south and north respectively).

$$
\begin{aligned}
& \text { ya } \quad x-m o-\phi \quad \text { ta lum } \\
& \text { ICP ASP-ascend-3A PREP Tenejapa_Center } \\
& \text { 'He's going up to Tenejapa Centre' (i.e., ta } a j k \text { 'ol) } \\
& \text { melel la nax laj s-le'on tal, } \\
& \text { truly CMP just QUOT 3E-search_for-1A comeDIR } \\
& \text { ' "Really, he said he just brought me here (as his wife), } \\
& \text { jich laj ko-em- } \phi \quad \text { s-kera-on nax laj } x i \\
& \text { thus QUOT descend-PPrt-3A 3E-servant-1A just QUOT 3E-said } \\
& \text { thus I just came down (here, from an 'uphill' paraje) as his } \\
& \text { maidservant," he said' }
\end{aligned}
$$

The distinction between an uphill/downhill reading and a vertical reading is given contextually, as is (in the absence of a deictic directional) whether the prepositional phrase should be read as referring to goal or source.

5 Aspectual 'motion': laj, lijk, jajch Finally we come to three Tzeltal verbs which, rather than denoting motion proper, indicate aspectual characteristics of actions: lijk 'begin', jajch 'begin, arise' and laj 'finish; die'. (These are in addition to $o c h$, which, as we have seen, can be used to mean 'begin' or 'enter into' an action or state.)

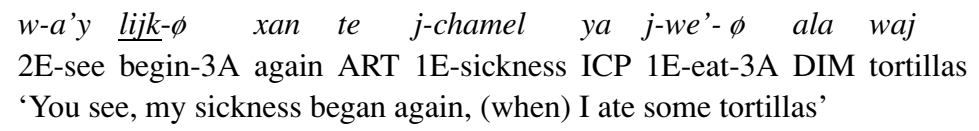




$$
\begin{aligned}
& \text { ya } x \text {-laj- } \phi \quad a \text { 'yej } \\
& \text { ICP ASP-finish-3A speech } \\
& \text { 'The gossip will finish' } \\
& \text { ya } x \text {-jajch-on ta a'tel ta bwen sab } \\
& \text { ICP ASP-arise-3A PREP work PREP really morning } \\
& \text { 'I get up/begin working very early' }
\end{aligned}
$$

These three verbs fall into the closed class with the motion verbs described above because together they exhaust the class of roots that can form auxiliaries and directionals. Semantically they also share features with the motion verbs, since their semantics can be described in terms of a trajectory and other reference point. The path distinctions encoded in this closed-class set of verbs are graphically illustrated in Figure 7.4. The three kinds of forms that these roots can take - as motion verbs, auxiliaries and directionals - either alone or in combination with other verbs (including other motion verbs) provide a system for specifying in detail the path and direction of movements through space, not only of animate things moving themselves by their own volition but also of inanimate things being moved (by the volition of animates, or by natural forces such as gravity or wind) ${ }^{27}$ As in verb-framed languages, spatial description is normally restricted to one prepositional phrase per clause, but the verb itself may express a complex path by virtue of combinations of verbs, auxiliary and directionals (see example 77 below).

Motion vs. stasis As we have seen, the system of motion verbs, directionals and auxiliaries is well designed for describing nuances of movement in relation to a locational point of reference which may be, in the case of deictic verbs and directionals, deictically anchored to the location of speaker/hearer in the speech situation. This motion system appears to have little in common semantically with the system for static descriptions, and in which, as we saw, deictic descriptions are dispreferred, and the dispositionals carry elaborate features of the shape, configuration, animacy, consistency, texture, etc., of the figure object. In contrast, the shape and configuration of objects is not attended to at all in these basic motion verbs. Apparently, anything in the Tzeltal world which can be appropriately described in stasis by any one of the several hundred dispositional adjectives is, the moment it moves, appropriately described by one or more of this handful of motion verbs and directionals.

However, motion and spatial configuration may be combined in several ways. First of all, it is perfectly grammatical to use a dispositional adjective to

${ }^{27}$ For example, the verb ich' 'to receive or obtain (it)', with the addition of a directional tal or bel becomes attuned to the direction in which the receiving occurs: ich' tal means 'to bring it', but ich' bel 'to take it'. 


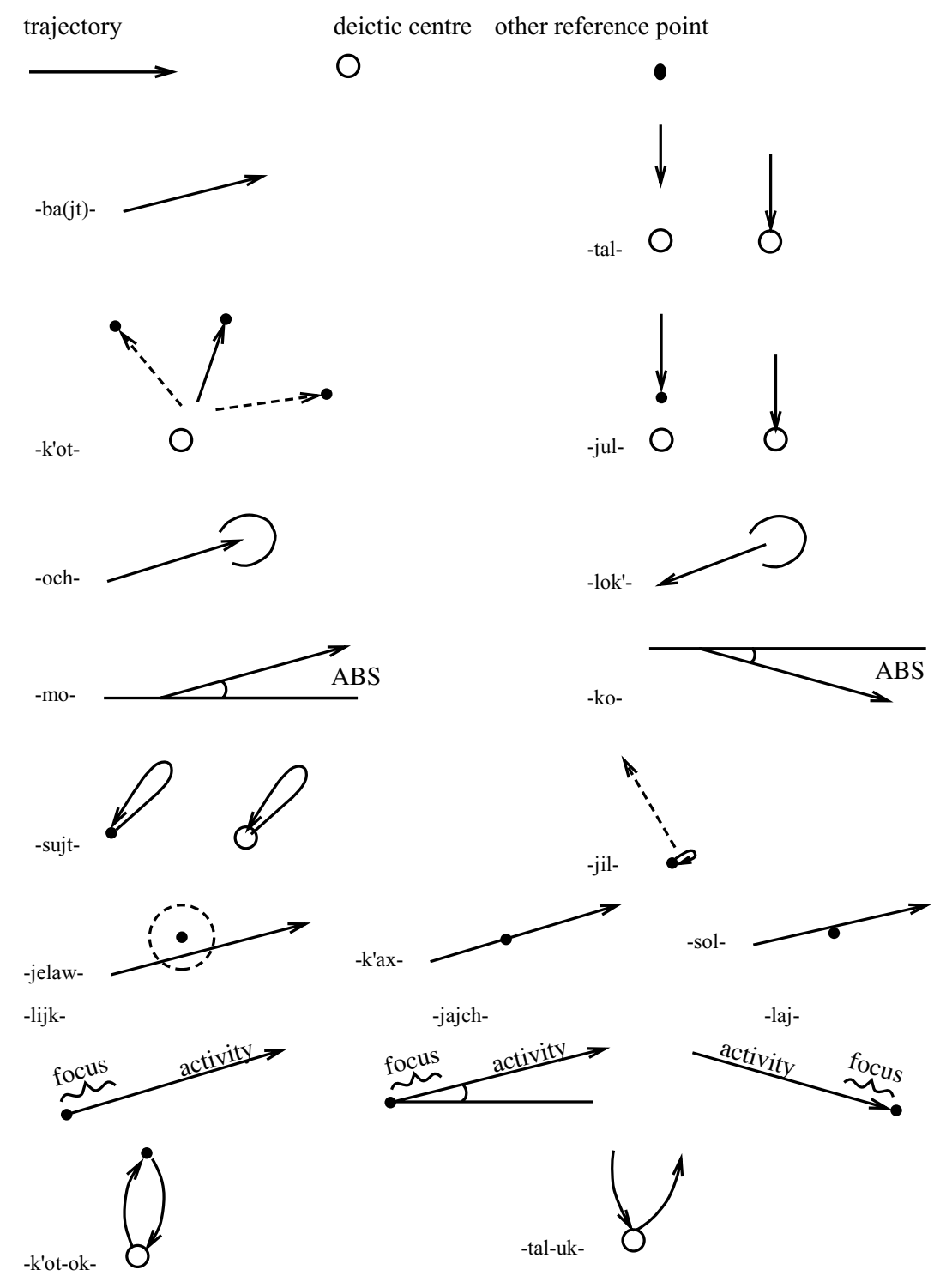

Figure 7.4 Path semantics in Tzeltal motion verbs 
indicate the figure's position in a description of its movement, as, for example, in describing a human crawling as 'move four-leggedly':

$$
\begin{aligned}
& \text { kotol- } \phi \quad \text { ya } x \text {-mo- } \phi \\
& \text { standing_on_all_fours-3A ICP ASP-ascend-3A } \\
& \text { 'He's going uphillwards four-leggedly' (i.e. on hands and knees) }
\end{aligned}
$$

It is also possible to include a directional to provide orientation in describing a static configuration:

$$
\begin{aligned}
& \text { jip-ajtik tal koel ta xujkxujk (mexa) } \\
& \text { hang-DIST comeDIR descendDIR PREP side-side (table) } \\
& \text { (te pak'-e) } \\
& \text { (ART cloth-CL) } \\
& \text { 'It (the cloth) is hanging downwards on all sides (of the table)' } \\
& \text { (TRPS 29) }
\end{aligned}
$$

Secondly, positional roots can be derived into transitive and intransitive stems, with the general meaning 'to put something into that position' (for transitives), or 'to be in that position' (for intransitives), e.g., bal-ch'oj 'to roll' (as in (76) below), joy-p'ej, 'to twirl', jaw-tz'oj, 'to fall face up', etc. The positional verb in these cases retains the semantic specificity of the root. ${ }^{28} \mathrm{It}$ is remarkable that, as a result, Tzeltal does not seem to exhibit the relation proposed as universal by Talmy (1983) - that a point figure in motion is treated as semantically parallel to a static linear figure. In Talmy's English example, he notes that The ball rolled across the path uses the same preposition across as The snake lay across the path. These two propositions would be expressed in Tzeltal by two quite different constructions - a finite verb construction designed for motion description, a dispositional adjective one for static configuration (of course, all spatial descriptions in Tzeltal use the same preposition, since there is only one!):

$$
\begin{aligned}
& \text { ya } x \text {-balch'oj- } \phi \text { jelawel ta be te pelota-e } \\
& \text { ICP ASP-roll-3A crossDIR PREP trail ART ball-CL } \\
& \text { 'The ball rolls across the path' }
\end{aligned}
$$

in contrast with:

28 Transitivized positional roots are a major resource for caused motion verbs - verbs of placement. There is no dedicated 'put' verb (although the verb $a k$ ' is general across 'put' and 'give' situations), but more usually a transitivized positional is used, indicating how the object will end up positioned once it has been placed. Many of these were used in our space games, for example in instructing a matcher how to place pieces of tinker-toy in a photo-matching task: e.g. sejpana 'place it flat-disk-shaped', lujchanbe ta sjol 'perch it on top of it', tejk'ana 'stand it up vertically', k'ajtanbe jelawel 'place it on it crossing acrossways'. 


$$
\begin{aligned}
& \text { k'atal- } \phi \text { ta be te chan-e } \\
& \text { crosswise-3A PREP path ART snake } \\
& \text { 'The snake is positioned across the path' }
\end{aligned}
$$

There is, however, one way in which Tzeltal can treat a static linear extension equivalently to a motion path - by reduplication of a body-part term that can be construed as extending linearly (namely, $x u j k$ 'side, corner', $t i$ ' 'mouth/lip/edge' and pat 'back'). Reduplication conveys 'along' the body part, as in example (66) above, and in:

chojt-ajtik- $\phi$ ta ti'-ti' soral te karo-etik-e 4_legged_standing PREP lip-lip street ART car-PL-CL

'The cars are standing (i.e. parked) along the edge (lit. 'at edge-edge') of the street.'

ya $x$-ben- $\phi \quad$ bel $y$-u'un ala pat-pat koral bel ICP ASPwalk-3A goDIR 3E-REL DIM back-back fence goDIR 'He walks away along the back (lit. 'in relation to back-back') of the fence' (route2.)

Dispositionals can also convey associated configuration during or as a result of motion. Tellings of the 'Frog Story' (see Chapter 1, §1.4.3) illustrate this well; while the overall movement from house through field and woods is generally expressed with a motion verb (e.g. ba 'go', animaj 'run', been walk', an 'flee'), when a scene is considered statically, dispositionals abound:

Extract from Frog Story told by AO, age 41 (dispositionals underlined)

in te ala kerem-e, kajal- $\phi$ ta

DEIC ART DIM boy -CL mounted_on-3A PREP

j-jejt te,

one-NCforked_branch tree

'As for the little boy, he's mounted onto a forked branch of a tree'

lutul- $\phi \quad t a$ j-jejt te'

wedged_between-3A PREP one-NCforked_branch tree

'He's wedged between the forks of the branch'

ajj:: te'tikil chij! lutul- $\phi \quad$ ta $x u l u b$

oh woodland sheep wedged_between-3A PREP horn

'Oh, it's a deer!' He's wedged between its horns.'

in te kerem, jip -ot te te'tikil chij DEIC ART boy throw_underhand-PASS ART woodland sheep 'As for the boy, he's been thrown by the deer' 
jip -ot jawal- $\phi$

throw_underhand -PASS lying_face_up_arms_outstretched-3A

ta lum,

PREP ground

'He's been thrown spread-eagled face-up to the ground,'
s-bech-lay-ej
$y-o k$
$s-k^{\prime} a b$

ASP-bend-DIST-STAT 3E-lower_limb 3E-arm

'he has out-stretched his arms and legs'

$j m$, in te tz' $i$ ' kojkoltza'- $\phi \quad$ butul- $\phi$

hm DEIC ART dog turned_upside_down-3A tipped_over-3A,

'Hm. As for the dog, he's upside-down tipped over'

jm, metzel- $\phi-i x$ ta lum

hm lying_down-3A-CMPL PREP earth

' $\mathrm{Hm}$. He is now lying on his side on the ground'

aj, 0 ch'ay- $\phi$ koel jawal- $\phi$

ah, CMP fall_down-3A descendDIR lying_face_up_arms_out-3A

niwan ek

perhaps also

'Ah, he's fallen down face-up-spread-eagled perhaps'

Further, even during motion description attention is often drawn to dispositional configurations if the position is non-canonical (e.g. 'fallen down', or 'tipped over'). ${ }^{29}$

Thirdly, motion semantics can enter into static descriptions when a static configuration is described from the perspective of how things got into that particular position. For example, many responses to our Where-questions and photograph description tasks included a directional element, implying that the state being described results from a directional action or has a visibly directional aspect:

kojkoltza' ay- $\phi \quad$ tal (te') upside down EXIST-3A comeDIR (tree)

'(The tree) is upside down coming' (i.e. fallen downwards towards where we are on a steep hillside)

ch'ikbil- $\phi \quad$ moel jo'joch ta oy having-been-stuck-in-3A upwards cornhusk PREP housepost.

'The cornhusks are stuck in, upwards, at the housepost' (i.e. they have been inserted/jammed behind the post, and vertically stacked)

29 See Brown 2000, 2003, for additional examples. 
cholol- $\phi \quad$ moel sok ta k'atal

positioned_in_row upwards plus PREP acrossways

'they are positioned in a row upwards andacrossways' (description of almonds placed in rows in an L-shaped configuration)

jok'ol- $\phi$ tal koel laso.

hanging-3A coming downwards rope

'The rope is hanging down towards us'

Indeed, it may be that the main motivation for using directionals in these contexts is to import a deictic reference point, which is otherwise scarcely used in static location description in Tzeltal. Finally, descriptions of motion are sometimes analogized to stasis, as in the uses of dispositionals in:

$$
\begin{array}{lllll}
\text { pek'el- } \phi & \text { ya } & x \text {-ko- } \phi & t a l & \text { sik' } \\
\text { low_down-3A } & \text { ICP } & \text { ASP-descending-3A comeDIR bird_sp. }
\end{array}
$$

'The birds are descending low downwards towards here'

$$
\begin{array}{lllll}
k \text { 'atal- } \phi & \text { ya } & x \text {-mo- } \phi & \text { bel } & \text { ch'ail } \\
\text { crossways-3A } & \text { ICP } & \text { ASP-ascend-3A } & \text { goDIR smoke }
\end{array}
$$

'Crossways the smoke rises awaywards' (i.e. the kitchen smoke appears to rise diagonally, due to light filtering through boards)

\subsection{Frames of reference}

Section 7.3.2 above provided a sketch of the core resources for describing static scenes, including the use of body-part expressions in prepositional phrases. These expressions have two uses: as topological relators (when figure and ground are in contact), and as means of expressing the intrinsic frame of reference (when figure and ground are separated). The intrinsic uses are very constrained, as Tzeltal speakers prefer to use body-part expressions when figure and ground are in contact or at least in close proximity. In the case where figure and ground are more widely separated in space, Tzeltal speakers use an absolute frame of reference to describe the angle at which the figure lies from the ground. Here I will sketch the linguistic resources for the Tzeltal absolute system.

\subsubsection{The 'uphill'/downhill' absolute system}

In Section 7.3 we focussed on the Tzeltal system of locative expressions in which a dispositional predicate and a prepositional phrase, amplified optionally with a possessed body-part expression, is used to specify the location of objects in space. We noted in passing that the terms ajk'ol ('uphill') and alan ('downhill') can be used in their possessed form analogously to body parts and other relational nouns to indicate a location 'above' or 'below' a particular relatum. This, however, is not the central usage of these terms, for ajk'ol and 
alan provide the basis for another system for locating both objects and actions (including motions) in space, namely an absolute coordinate system. In its core usage $a j k$ 'ol indicates the general lay of the land upwards, which in Majosik' is approximately towards the south, and alan indicates the direction in which the land falls away towards the river Tanate' which bounds Tenejapa to the north. The orthogonal direction across the overall lay of the land is designated as $t a$ jejch, i.e. crossways across the valley/ridge, either in the east or west direction - which direction only being specifiable gesturally or in terms of a salient landmark (a mountain, school, or the direction of sunrise vs. sunset, for example). This coordinate system, although based on the local geography (roughly a series of north/south running valleys), is now abstracted from it and therefore applicable even on the horizontal; it applies at all scales from the far distant to very local, even reachable, space. (See Figure 7.5.) It does not, however, usually extend down to body space (i.e. one does not normally in Tzeltal distinguish a person's left and right eyes, cheeks, arms or legs, as 'the one uphill' vs. 'the one downhill').

The details of this system are explored in Brown and Levinson 1993a, Levinson 2003; here it will suffice to indicate the essential nature of the system and how it differs from the others we have been describing. As we noted:

[T] he terms label angles, fixed without reference to the orientation of ego or another human body, with which one can describe relative positions. They are used in this way routinely to describe the locations of things, either with respect to each other or with respect to protagonists or speakers, on both a large scale (locations in the landscape), and on a small scale (locations within, say, arm's reach). (Brown and Levinson 1993a: 7)

The ajk'ol/alan axis, running south/north, along with the orthogonal jejch axis further specified by geographical landmarks (e.g. well-known mountains or cliffs) or by reference to the passage of the sun, provide a set of coordinates which speakers can use to specify the location of objects or the direction of motion of people and things around them. This is an absolute system of spatial reckoning which contrasts with the intrinsic system described above, where objects are located by means of their position or their configuration vis-à-vis the parts of a ground object. Tzeltal speakers readily employ both systems in everyday usage.

Such an absolute system also contrasts significantly with a relative coordinate system based on body-projection, and requires speakers to be absolutely oriented at all times, for it is used not only in the local territory (where overall 'uphill' and 'downhill' are obvious directions) but also on the flat and in unfamiliar territory. In San Cristóbal, the market town some twenty miles from Majosik', even not widely travelled Tzeltal speakers flawlessly indicate the direction of (absolute) ajk'ol and alan without a moment's hesitation. 

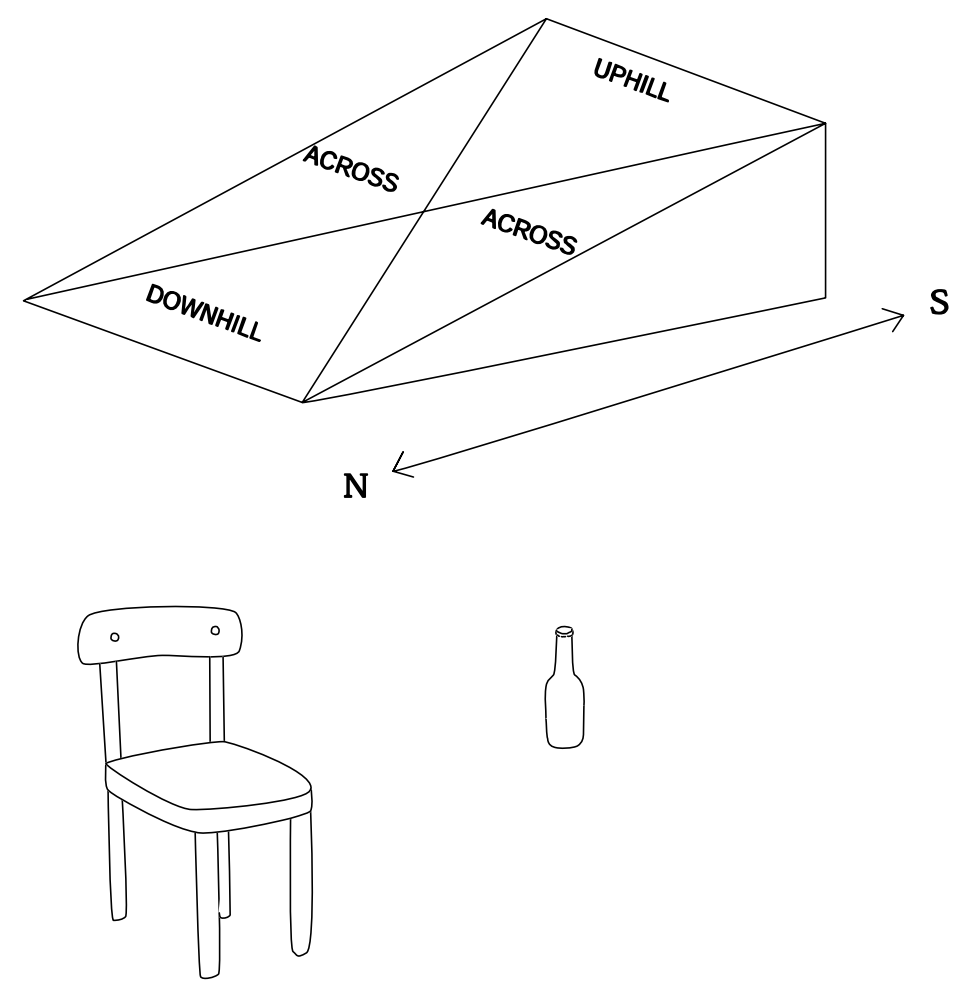

'The bottle is uphill of the chair'

Figure 7.5 The Tzeltal uphill/downhill system

The lexemes alan and ajk'ol are nouns; they therefore can appear in locative expressions with the existential predicate $a y$, with or without the preposition ta; for example:

$$
\text { ay- } \phi \quad \text { ta ajk'ol te limete }
$$

EXIST-3A PREP uphill ART bottle

'The bottle is to the uphill' (i.e. of another one, on a table)

$1 ;$ ta olil lek ay- $\phi$ ?

PREP middle good EXIST-3A

'Is it right in the middle?'

a; ju'uk tey ay- $\phi \quad$ ala ajk'ol tebuk. ma ba olil no there EXIST-3A DIM uphill a_bit. NEG middle 'No, it's a little bit uphillwards. Not in the middle' 
In these examples, what is indicated is that the figure is located more uphill than its reference point, which, if unstated, may be the speaker or some contextually given other object. The reference point can be explicitly stated, as in:

$$
\text { ay- } \phi \text { ta ajk'ol a'w-u'un/k-u'un te limete }
$$

EXIST-3A PREP UPHILL 2E-REL/1E-REL ART bottle

'The bottle is uphill in relation to you/me'

$$
\text { ay- } \phi \quad \text { ta } y \text {-ajk'ol te' te limete }
$$

EXIST-3A PREP its-uphill tree ART bottle

'The bottle is uphill from the tree'

A special derived form of $a j k^{\prime} \mathrm{ol}$ - possessed and with a - $V l$ suffix added - means 'vertically above', and the reference point is the possessor:

ay- $\phi \quad k a j a l$ ala j-ch'ix te' ta y-ajk'ol-al

EXIST-3A on_top_of DIM one-NC stick PREP 3E-uphill-Vl

'There is a little stick on top of it' (i.e. on its -ajk'olal or topmost surface or region)

The ajk'ol/alan axis, and its orthogonal ta jejch, are used for spatial reference regardless of the distance from speaker/hearer. Hence we find tabletop uses, this being, for example, a natural way to distinguish, Photos 2.3-2.5 in our Men and Tree picture-description tasks. The following descriptions are by a speaker facing west, with north (downhill) to her right, south (uphill) to her left (see Chapter 1, Figure 1.3).

\section{(pppetmar)}

Photo 2.3:

sok xan jtul winik, jich tek'el ta ajk'ol ine. jich ay jtejk te' jich ta alan ine. te winike, jich ya xk'aboj koelix ta alan ine.

'And again one man, he's standing uphillwards here. There's a tree thus it's downhillwards here. The man is looking downhillwards towards downhill here.'

Photo 2.4:

sok xan winik, tek'el. jich ya xk'aboj moel ta ajk'ol ine, sok jtejk te' jich ta spat ine.

'And again a man, standing. He's looking uphillwards towards uphill here, and a tree is thus here at his back.' 
Photo 2.5:

sok xan jtejk te' jich tekel ta ajk'ol ini. te kereme, jich ay ta alan ini. jich ya xk'aboj moel ta ajk'ol ine.

'And again one tree standing uphillwards here. The boy, thus he's downhillwards here. Thus he is looking uphillwards towards uphill here.'

The use of 'uphill/downhill' for this distinction depends of course on the absolute orientation of the players; another pair oriented differently (facing downhill, with the undifferentiated 'across' axis to be distinguished in the description) described Photo 2.4 thus:

(ppxunpet)

Photo 2.4:

p: ja' nanix te winike. tek'el xan. sok nanix te ste'e. sok xan te jtejk te ala te'e, tek'elix ta spat. swalak'patiyej. jm. jich ya xbajt ta mali k'al yilel te winike. jich ya xk'abu bel ini, li' ta banti ya xch'ay k'al yileli.

'It's the man again, standing again, with his stick. And the little tree again, standing at his back. He has turned his back to it. Hm. Thus the man is going towards where the sun sets, it appears. Thus he's looking awaywards here, here to where the sun falls, it appears.'

$\mathrm{x}$ : jm, li' ay ta ba'ay ya xlok' tal k'al eki te'i?

'Hm, here where the sun rises is the tree?'

p: tey.

'There.'

Naturally occurring examples of the absolute system used for small-scale spatial description are not hard to find, as when a mother told her three-year-old, struggling to put a puzzle-piece into its correct hole:

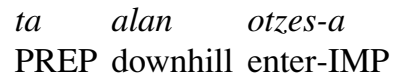

'Put it (puzzle piece) in downhillwards (in the downhillwards hole)'

Indeed, we find 'uphill'/'downhill' descriptions at all scales from the tabletop and beyond:

a. banti ay- $\phi \quad$ te machit?

where EXIST-3A ART machete

'Where is the machete?' 
b. li' ay- $\phi \quad$ ta $y$-ajk'ol ti'nail.

here EXIST-3A PREP 3E-uphill door

'Here it is at the uphill side of the doorway' (about 6 feet away from speaker)

a. banti ay- $\phi$ te kosina-e?

where EXIST-3A ART kitchen-CL

'Where is the kitchen?'

b. $l i$ 'ay- $\phi$ ta alan

here EXIST-3A PREP downhill

'Here it is, downhill' (i.e. 10 metres away, downhill)

a. banti ay- $\phi$ te s-na xi'lel Antun?

where EXIST-3A ART 3E-house ElBr Antun

'Where is brother Antun's house?'

b. li' ay- $\phi \quad s-n a \quad l i$ ' ta alan

here EXIST-3A 3A-house here PREP downhill

'Here is his house here downhill' ( + pointing in the northerly

direction; the house is about a half a mile away, and out of sight)

These examples give an indication of how ajk'ol/alan terms are used, and over how broad a terrain they may extend, from the very local to the very far away. They don't, however, reveal one serious complexity, namely that given instances of usage do not in themselves reveal exactly what the alan/ajk'ol axis is taken to be. Aside from its probably derivative use to supply a vector on the vertical dimension, where ajk'ol means vertically upwards or above and alan means vertically downwards or below, the alan/ajk'ol system can be used in three distinct ways to specify a vector on the sloping or inclinedplane dimension: (1) The angle specified by these terms may be the absolute, fixed angle (corresponding roughly to north/south); this is the basic usage. (2) It may be given by the local inclination of the terrain which, because of local hills, cliffs, etc., does not necessarily coincide with the overall drop from south to north. (3) The uphill/downhill absolute system can occasionally be detached from its geographical coordinates and employed relatively, although we found evidence of this only in certain very constrained elicitation contexts (e.g. placement tasks or matching games) not in naturally occurring situations. ${ }^{30}$

${ }^{30}$ For example, when describing the relative locations of two bottles arrayed on the sagittal (front/back) axis, one speaker used ajk'ol to mean 'farther away from me (or you), along my (or your) sightline' and alan to mean 'closer to me/you, along my/your sightline'. (See Brown and Levinson 1993a for details.) (This is analogous to the use of up/down on the sagittal axis for English speakers.) A few other speakers adopted the same strategy in other elicitation tasks and space games, although it was always a minority, last-ditch strategy; this minority deictic 'uphill'/'downhill' strategy was not associated with deictic uses of 'left-hand' and 'right-hand' terms. 
In this marginal usage, it may be the deictic angle defined by the orientation of the speaker's (or addressee's) body, indicating something like 'nearer or farther in front of me/you'. These different usages are generally appropriate to different scopes of spatial description. Thus, in descriptions of things more than a few metres away, the cardinal-absolute usage predominates. When a local activity (e.g. chicken-feeding, planting, house-building, tree-felling) is at issue one may get a local-inclination system predominating (since it specifies the inclination relevant to the activity at hand). Finally, the relative usage appears to be a derivative use of ajk'ol and alan, limited to the rather peculiar context of differentiating identical objects placed very close to each other on a table in front of the speaker with the constraint that simple pointing was disallowed (i.e. the usage may have been forced on consultants by our elicitation procedures). The unmarked usage of tay-ajk'ol and ta y-alan is to indicate the location of objects (relative to some reference object) absolutely oriented in relation to the overall lie of the land.

We have already seen that the alan/ajk'ol system interacts with the dispositional system in so far as certain relational nouns (namely, ta y-anil 'at its underneath' or 'below') or dispositionals ( $t a$ kajal 'at its above' or 'abovewards') have taken on uphill/downhill meanings and can now be used interchangeably with alan and ajk'ol in some contexts. But, unlike the dispositionals, which are specialized for static descriptions of location, the ajk'ol/alan axis may equally be used to describe direction of movement.

$$
\begin{aligned}
& \text { ya } \quad x \text {-ba-on } \quad l i \text { ' nax ta ajk'ol-i } \\
& \text { ICP ASP-go-1A DEIC just PREP uphill-DEIC } \\
& \text { 'I'm just going towards uphill a bit' }
\end{aligned}
$$

Instead of (or in addition to) ajk'ol, however, one may use the directional moel, even for static descriptions. For example, the following was used to describe the static configuration of a pot with a feather south of it and a stick balanced on top of it:

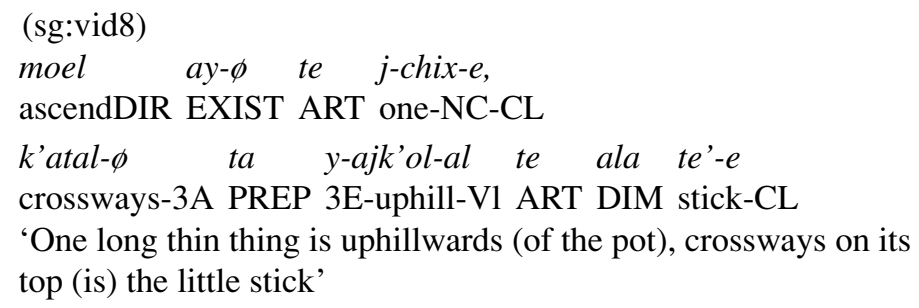

By the same token, the directional koel may likewise be used instead of alan: 
PREP descendDIR EXIST-3A ART NEG

$s$-ta-oj- $\phi$ semento-e

3E-encounter-STAT-3A cement-CL

'The one that doesn't touch the cement is downwards (of it), (i.e. north)'

There is, however, a contrast between koel and ta alan when motion rather than stasis is involved: either koel or ta alan may be used for the downhillwards direction, but koel rather than ta alan is used for 'down' in the vertical dimension. For example, in the process of building a chicken house one man instructed another to pull the chicken wire vertically downwards, with koel:

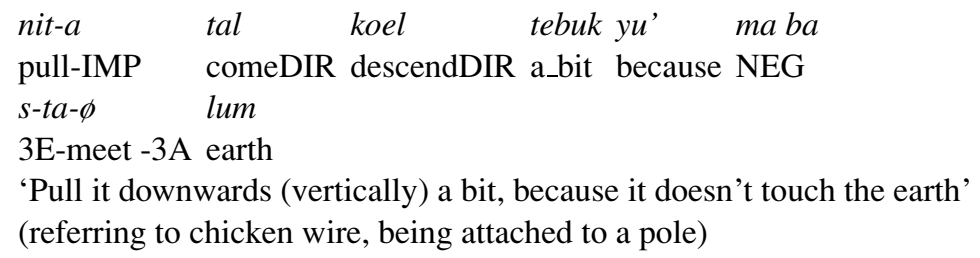

When instructing another to pull it sideways from another position towards the downhill direction, however, he said:

$$
\begin{aligned}
& \text { nit-a koel tey ta alan } \\
& \text { pull-IMP descendDIR there PREP downhill } \\
& \text { 'Pull it downwards there towards downhill' (i.e. northwards) }
\end{aligned}
$$

\subsubsection{Absence of a relative (front/back/left/right) system}

There is no relative system available in Tenejapan Tzeltal, based on oppositions for which the projections from the body provide a coordinate system. ${ }^{31}$ Marginal deictic or relative uses of certain terms in the intrinsic and absolute systems, as described above, do not constitute a full-blown relative system. There is no systematic use of a deictically based front/back projection, although there are marginal deictic uses of certain terms (pat 'back', stojol 'its-front' of a non-featured object, as described above). Two objects arrayed on the front/back axis can be, however, readily distinguished by the directionals bel/tal 'going'/'coming', the object closer to the speaker being described as 'coming', that farther away as 'going'. They can also be distinguished by deictic demonstratives or adverbs. There is no corresponding deictic or relative

31 Casual observation of a few bilingual Tenejapans suggests that they do not use a relative system even when speaking Spanish, although further research would be required to establish this conclusively. 
possibility in Tenejapan Tzeltal for the axis orthogonal to front/back. There is no propensity at all to use the terms for 'left hand' (xin k'ab) and 'right hand' ( $w a^{\prime}$ el $k^{\prime} a b$ ) to indicate the corresponding relative projected regions of a ground object. We did find just once the use of the Tzeltal body-part terms for left and right hands used to ascribe the angle at which an object or person was to be located, but this was not allocated deictically. This occurred during one session in our photograph-matching games. The perspective adopted was that of the person in the photograph, not the viewer (i.e. the animal being described was just next to the person in the photograph's left/right hand, so both the relatum and the origo of the coordinate system was the photographic person, not the speaker). We have never heard Tzeltal 'left'/'right' being used with the speaker as origo for a left/right ascription in relation to some other (non-speaker) relatum, nor was it ever used to describe a figure related to an inanimate ground, and in no cases was left-right used to describe a region as opposed to immediate adjacency. (See Brown and Levinson 1992, Levinson and Brown 1994).

\subsection{Conclusion}

We have described the resources available in Tzeltal for spatial description. We have seen that, with only one preposition, spatial description of static scenes relies heavily on 'dispositional' predicates incorporating features of shape/configuration/position, etc., to indicate properties of the figure and/or the precise spatial relation to some ground object. This specificity vanishes in the motion roots, which encode pure Motion + Path with no information provided about the figure (unless via incorporation of a positional root into a larger construction.) This suggests (contrary to Landau and Jackendoff 1993) that the 'what' and the 'where' systems are not linguistically allocated to two distinct linguistic systems in Tzeltal (e.g. nouns vs. prepositions) but merge for descriptions of location, although apparently not for motion. And then, even motion scenes may be described from the point of view of resultant position.

We have also seen that only two frames of reference are routinely used in Tzeltal: the intrinsic for situations where figure and ground are immediately adjacent; the absolute in most other cases. There are only marginal uses of deictic or relative projections from these two systems for the front/back axis (but never for the left/right one); the fact that these deictic projections do sometimes occur, however, makes it clear that Tenejapans retain this as a cognitive possibility along with the other two frames of reference. Despite the heavy reliance on the intrinsic and absolute frames of reference, and the relative neglect of deixis as the basis for elaborated spatial descriptions, we do find deixis creeping into Tzeltal spatial descriptions, in several ways: (a) with demonstratives, deictic adverbials and gestural deixis; (b) with deictic relata for uphill/downhill descriptions 
(e.g. 'uphill of me/you'); (c) with deictic possessors of body-part terms and relational nouns (e.g. 'at your/my belly'); (d) with deictic uses of 'up'/'down' (e.g. 'it is above' - meaning 'farther from me'), and, especially, (e) with the directionals tal 'coming' and bel 'going'.

These Tzeltal findings, especially those of a relative de-emphasis on deixis and left/right asymmetry, are consonant with other characteristics of Tenejapan life and ethnography. These include an aesthetic which favours symmetry and a lack of left/right distinctions permeating Tenejapan life, showing up in interactional space (e.g. in gesture), in weaving patterns, in architecture, in ritual practices, as well as in psychological tasks which reveal a tendency to 'mirrorimage blindness' (that is, to treat left/right mirror-image reversed images as identical) (Brown 1991, 2002, Brown and Levinson 1992, 1993a, Levinson and Brown 1994).

We have also found that the use of the absolute system correlates systematically with performance on non-linguistic tasks. Tenejapans tend to remember and reason about spatial relations in terms of their 'uphill'/'downhill' frame of reference (Brown and Levinson 1993a, Levinson 1996b, Levinson 2003), supporting the conclusion that there are important cognitive consequences of a frame of reference that is routinely employed (see also Pederson et al. 1998). A third finding is that Tenejapan children learn their absolute system relatively early, being able to understand absolute spatial descriptions by the age of four, and being able to competently produce them in novel situations in tabletop tasks by the age of six or seven. ${ }^{32}$

These results are at least suggestive of a quite different conceptualization of spatial relations in Tzeltal language and culture from that which has been posited as universal, and as based on an egocentrically defined abstract space constituted by three planes defined in relation to the human body (one vertical up/down, one horizontal front/back and one horizontal left/right). In Tzeltal language use, as we have seen, the human body does not appear to divide space up in this egocentric way; rather, spatial relations are described in large part very specifically, in terms of the gestalt presented by the configuration of a figure positioned in a ground, with further specification provided optionally by body-part terms. Further specification of vectors or direction of orientation can be done using the absolute system. This uphill/downhill system brings in a more abstract conceptualization of space than does the orientation-free Intrinsic system, one that can also be used for motion description.

32 See Brown 2001, Brown and Levinson 2000, for the Tzeltal acquisition details. See de León 1994, 1997, 2001, for analogous findings for Tzotzil. 